\title{
Mass Spectrometry and Glycomics
}

\author{
Joseph Zaia
}

\begin{abstract}
Glycosylation defines the adhesive properties of animal cell surfaces and the surrounding extracellular environments. Because cells respond to stimuli by altering glycan expression, glycan structures vary according to spatial location in tissue and temporal factors. These dynamic structural expression patterns, combined with the essential roles glycans play in physiology, drive the need for analytical methods for glycoconjugates. In addition, recombinant glycoprotein drug products represent a multibillion dollar market. Effective analytical methods are needed to speed the identification of new targets and the development of industrial glycoprotein products, both new and biosimilar. Mass spectrometry is an enabling technology in glycomics. This review summarizes mass spectrometry of glycoconjugate glycans. The intent is to summarize appropriate methods for glycans given their chemical properties as distinct from those of proteins, lipids, and small molecule metabolites. Special attention is given to the uses of mass spectral profiling for glycomics with respect to the $\mathrm{N}$-linked, $\mathrm{O}$-linked, ganglioside, and glycosaminoglycan compound classes. Next, the uses of tandem mass spectrometry of glycans are summarized. The review finishes with an update on mass spectral glycoproteomics.
\end{abstract}

\begin{tabular}{|c|c|}
\hline Abstract & 401 \\
\hline Introduction & 402 \\
\hline Mass spectral ionization methods & 402 \\
\hline Mass spectrometry of glycans & 403 \\
\hline Ionization & 403 \\
\hline Chromatographic interfaces for mass spectral glycomics & 403 \\
\hline Capillary electrophoresis of glycoproteins and released glycans & 404 \\
\hline Ion mobility MS applied to glycomics & 404 \\
\hline Mass spectrometry of high molecular weight glycoconjugates & 405 \\
\hline Mass spectral glycomics profiling & 405 \\
\hline Approaches without stable isotope labels & 405 \\
\hline$N$-linked glycomics & 405 \\
\hline O-linked glycomics & 406 \\
\hline Human milk glycomics & 406 \\
\hline Stable isotope labels for glycomics & 406 \\
\hline Permethylation labeling & 406 \\
\hline Reductive amination & 407 \\
\hline Tandem MS and the analysis of isomeric glycan mixtures & 407 \\
\hline Lactosamine linkages & 407 \\
\hline Sialic acid linkage isomers & 407 \\
\hline Branching isomers & 407 \\
\hline Fucosylated isomers & 408 \\
\hline Determination of other disaccharide linkages & 408 \\
\hline Glycosaminoglycan isomers & 408 \\
\hline MS of glycopeptides & 408 \\
\hline Tandem MS of glycopeptides & 409 \\
\hline Collision-induced dissociation and infrared multiphoton dissociation & 409 \\
\hline Electron capture dissociation & 410 \\
\hline Electron transfer dissociation & 410 \\
\hline
\end{tabular}

Department of Biochemistry, Boston University, Boston, Massachusetts. 
Conclusions

Author disclosure statement 410

List of abbreviations used 411

\section{Introduction}

$\mathrm{G}$ LYCOCONJUGATE GLYCAN EXPRESSION is essential for embryogenesis (Haltiwanger and Lowe, 2004), development (Hacker et al., 2005), adult physiological processes (Bishop et al., 2007), and evolutionary survival of animal species (Varki, 2006). All animal cells express glycosylated proteins and lipids in abundance on their surfaces. Adherent cells synthesize extracellular matrices, essential components of which are glycoproteins and proteoglycans. It is now apparent that lectin domains in myriad proteins serve to define adhesive properties by virtue of carbohydrate-protein binding interactions. The structures of glycoconjugate glycans are regulated dynamically, resulting from biosynthetic reactions in the endoplasmic reticulum and Golgi apparatus that are under complex regulation. Because many of these reactions do not go to completion, glycans modifying an individual site are typically expressed as a mixture of glycoforms elaborating a core structure. This diversity multiplies the structural and functional complexity of proteins and lipids by orders of magnitude.

Glycans are now recognized as mediators of pathophysiological events related to progression of tumors (Dwek and Brooks, 2004; Fuster and Esko, 2005). To understand their roles in physiology and pathophysiology, the macro- and microheterogeneity of glycans is an impediment to the understanding of biological functions and the development of carbohydrate-based vaccines, drugs, and therapeutics (Bernardes et al., 2009; Seeberger and Werz, 2007). These approaches have enabled the development and use of carbohydrate microarrays (Blixt et al., 2004; Blixt et al., 2008; Feizi and Chai, 2004; Feizi et al., 2003; Liang et al., 2008; Seeberger and Werz, 2007). There is also considerable interest in the production of glycoproteins with defined homogeneous glycosylation structure (Bennett et al., 2008; Bernardes et al., 2009; Hsieh-Wilson, 2007) for therapeutic purposes.

Carbohydrate microheterogeneity may also be viewed as a hallmark of glycoconjugate function. Evolutionary development of multicellularity entailed the development of glycoconjugates that function to control the interactions among cells (Lauc, 2006). Extracellular glycans mediate cell-cell and cell-pathogen interactions (Varki, 2006). Intracellular O-GlcNAc modifications serve as a dynamic regulatory switch and nutrient sensor (Hart et al., 2007). Thus, the dynamic nature of glycosylation serves the need of long lived species to respond to rapidly evolving pathogens (Varki, 2006).

The development of methods for mass spectrometry (MS) of glycans is driven the two biomedical approaches outlined above. MS is capable of providing structural constraints for such purified molecules, although complete structural determination typically requires several analytical technologies including MS, linkage analysis, and NMR. MS methods are also used to maximize the structural information produced given limiting resources in terms of time, labor, and sample quantity. In "omics" fields, tasks are often divided between discovery and targeted analysis. Thus, determination of glycan masses is often an early step in profiling glycan expression related to a disease state. The masses of glycans released from biological source may be determined rapidly and with low sample consumption and high throughput. The resulting information reflects the abundances of all glycan compositions present and do not determine the abundances of individual glycan structures, because structural isomers are typically present. Combinations of separations and tandem mass spectrometry may be used to build information defining the structures of glycans present from product ion patterns. In many experiments, tandem mass spectra are acquired on glycan masses that represent mixtures of structural isomers. It is therefore important to learn to use such data, because it is not practical to purify all glycans of interest to homogeneity.

This review summarizes mass spectrometry-based approaches for glycomics. Such methods divide generally into mass profiling, in which the masses and abundances of released glycans are determined and compared among a set of sample and fine structure determination, in which detailed structures are determined. The discussion emphasizes approaches that are designed to produce structural information while consuming minimal quantities of material. Such approaches have the sensitivity to meet the needs of biomedical scientists for glycan analysis.

\section{Mass Spectral Ionization Methods}

Although fast atom bombardment ionization was used to develop many of the principles of modern glycoconjugate mass spectrometry (reviewed in Zaia, 2004), the matrixassisted laser desorption/ionization (MALDI) (Karas and Hillenkamp, 1988; Karas et al., 1987) and electrospray ionization (ESI) (Meng et al., 1988; Whitehouse et al., 1985) techniques are used in the vast majority of published work today.

The chemistry of the carbohydrate monosaccharide residues strongly influences the ionization behavior of glycoproteins (Zaia, 2007). To a first approximation, animal monosaccharides are either neutral hexoses or $N$-acetyl hexosamines or they are acidic sialic acids, uronic acids, sulfated, or phosphorylated monosaccharide residues. Thus, glycoconjugate glycosylation tends to increase the acidity of glycocoproteins relative to the aglycon. Thus, glycosylation increases both the hydrophilicity and surface activity of the modified proteins and peptides. These effects strongly influence the ionization of glycoconjugates, relative to unmodified proteins or peptides. Thus, if analyzing a glycoprotein tryptic digest using positive ion mass spectrometry, the unmodified peptides will be least acidic and more likely to form abundant positive ions, with the result that the ionization of glycosylated proteins will be suppressed. As a general principle, samples to be analyzed using mass spectrometry should be 
separated into fractions of approximately equal acidities. Doing so minimizes the extent to which ion suppression occurs.

The use of MALDI mass spectrometry entails mixing the analyte with an acidic matrix and drying a low microliter volume on a metal target, forming crystals. Subsequent irradiation with pulsed laser light creates a molecular plume containing ionized analyte and matrix molecules that may be mass analyzed. It is important to note that acidic glycan residues dissociate to a substantial degree during the MALDI process. The result is that losses of sialic acid, sulfate, and phosphate residues are likely to be observed for native carbohydrates and glycoconjugates using MALDI.

The ESI process entails infusion of a solution containing the analyte through a sharp electroconductive needle to which is applied elevated electrical potential of positive or negative polarity. The analyte solution is thereby caused to form extremely fine droplets that readily evaporate to form analyte ions. The electrospray process is confers less vibrational energy on the analyte molecules with the result that fragmentation of glycoconjugates is generally not observed. ESI may be used either by direct infusion of an analyte solution or by direct connection to a liquid chromatography column.

\section{Mass Spectrometry of Glycans}

\section{Ionization}

Ionization techniques for mass spectral analysis of glycans have been reviewed recently (Zaia, 2006), and will be briefly summarized here. As with any chemical compound class, ion suppression effects are minimized when analyzing mixtures with equivalent chemical properties in terms of acidity and hydrophobicity. During ionization more hydrophobic compounds will generally suppress less hydrophobic compounds in a mixture. When analyzing compounds using positive ionization mode, basic compounds will suppress acidic compounds when analyzed as a mixture. The opposite is true when using the negative ionization mode. Thus, it is advisable to separate glycans according to acidity prior to mass spectral analysis. On-line liquid chromatography/mass spectrometry (LC/MS) accomplishes this by separating glycans according to their chemical properties prior to infusion into the mass spectrometer (Wuhrer et al., 2005a; Zaia, 2009).

Permethylation serves to render glycans hydrophobic, improving their MS ionization responses, and equalizing their chemical properties. Historically, carbohydrates were derivatized to increase their volatility and stability for MS analysis (Zaia, 2004). Permethylation of carbohydrates was perfected during the 1980s at a time when fast atom bombardment ionization was the best choice for analysis of biomolecules (Ciucanu and Costello, 2003; Ciucanu and Kerek, 1984). Permethylated carbohydrates are ionized typically as sodium cationized ions and are considerably more stable than native glycans. This fact that is of particular importance because it enables effective use of vacuum MALDI sources that are widely available on modern mass spectrometers.

MALDI MS is used extensively for analysis of glycan classes, as has been reviewed in detail (Harvey, 1999, 2003, 2006, 2008). Briefly, MALDI sample preparation methods are relatively tolerant of salts and other nonsurfactant additives or contaminants, with the result that data are obtained with minimal sample workup. One limitation to the use of MALDI for native and reductively aminated glycans is that a rela- tively high degree of vibrational excitation of the ions occurs during the ionization process (Moyer and Cotter, 2002; Moyer et al., 2002; O'Connor and Costello, 2001; O'Connor et al., 2002). As a result, there is a significant degree of fragmentation to fragile glycan substituents, including sialic acid and fucose residues, sulfate, and phosphate groups. Thus, great caution must be taken in the interpretation of such MALDI mass spectra because the observed ions may have dissociated to lose fragile substituents prior to detection. Permethylated glycans are considerably more stable than their native counterparts, and dissociation during the MALDI process is not a problem.

During the electrospray ionization (ESI) process, multiply charged ions are created during the relatively slow droplet desolvation process. The extent of fragmentation of acidic glycans and other fragile ions is much lower than observed using vacuum MALDI (Zaia, 2007). As a result, ESI is appropriate for direct analysis of acidic glycans for MS and tandem MS. Native glycans reside in the center of ESI droplets, and tend to be suppressed by more hydrophobic molecules. This suppression is minimized through the use of nanoscale ESI because the initial droplet size is smaller and there is less concentration of suppressing molecules (Karas et al., 2000). ESI produces inherently better resolved peaks for glycoconjugates due to the absence of matrix adduct peaks (Satterfield and Welch, 2005). ESI has the disadvantage that it is more labor-intensive than MALDI and produces a complex pattern of charge states. Samples must be free of salts prior to introduction into the ion source to avoid the problem of multiple cation adduction due to salts in the sample solution. This entails use of chromatography, either off- or online prior to ESI MS. Unfortunately, routine on-line LC/MS cannot be accomplished practically at the nano-ESI scale $(<50 \mathrm{~nL} / \mathrm{min})$.

\section{Chromatographic interfaces for mass spectral glycomics}

Readers seeking detailed summary of LC/MS approaches for determination of protein glycosylation are referred to the following reviews (Hirabayashi and Kasai, 2002; Wuhrer et al., 2005a). Quantitative measurement is facilitated by chromatographic separation of glycans prior to MS so as to minimize ion suppression effects. Although the structures of glycans separated by chromatographic retention time may be correlated based on retention time to a library of glycan standards (Guile et al., 1996; Knezevic et al., 2009), the use of a mass spectral detector facilitates the development of a retention time library against which unknown glycan compositions may be referenced (Pabst et al., 2007).

A number of methods for on-line LC/MS for glycans are practical. Reductive amination (Anumula, 2000, 2006) may be used to increase the hydrophobicity of glycans to enable use of reversed phase chromatography under MS-compatible conditions. Aminopyridine (Kuraya and Hase, 1996; Yamamoto et al., 1989), 2-aminobenzamide (Chen and Flynn, 2007; Royle et al., 2002) 1-phenyl-3-methyl pyrazolone (Mason et al., 2006; Saba et al., 2001) are widely used for derivatization of $N$-glycans for on-line LC/MS. The most highly retained compound is the unmodified reductive amination reagent. As the size and polarity of the glycan increases, the degree to which it binds the stationary phase decreases. 
Reversed phase ion pairing (RPIP) involves pairing acidic glycans with amine compounds in the mobile phase to permit interaction of the glycans with the hydrophobic stationary phase. RPIP has been used quite effectively for on-line LC/MS of glycosaminoglycans (Kuberan et al., 2002; Thanawiroon et al., 2004) and may also be used for analysis of glycans reductively aminated with a sulfonated alkyl group (Gennaro et al., 2003). The use of RPIP has the advantage that high chromatographic resolution is observed, albeit at the expense of having to infuse amine-containing mobile phase into the mass spectrometer source.

Graphitized carbon chromatography (GCC) separates compounds based on hydrophobicity and polarizability. For glycans, retention times increase as the glycan size increases and as the number of acidic groups increases. On-line LC/MS methods using packed capillary (Itoh et al., 2002; Kawasaki et al., 2003) and chip-based (Niñonuevo et al., 2005; Zamfir et al., 2005) GCC separation systems have been published for glycan classes. GCC has the advantage of comparatively high resolution resulting in separation of some types of glycan structural isomers. The most acidic glycans, including polysialylated, phosphorylated, or sulfated $N$-glycans and sulfated O-glycans including the glycosaminoglycans are highly retained using GCC and tend to be poorly recovered. Basic mobile phase conditions have been used to mitigate this problem (Estrella et al., 2007; Karlsson et al., 2004).

Hydrophilic interaction chromatography (HILIC) is effective for separation of native glycans according to size and polarity and has been used for on-line LC/MS analyses (Butler et al., 2003; Mattu et al., 2000; Royle et al., 2002). Capillary HILIC using amide silica has been used for on-line LC/MS of N-glycans (Wuhrer et al., 2004), glycopeptides (Wuhrer et al., 2005b), and glycosaminoglycans (Hitchcock et al., 2008; Naimy et al., 2008; Staples et al., 2009, 2010) and off-line for MALDI MS of glycosphingolipids (Zarei et al., 2008). HILIC has the advantage that it is applicable to all glycan classes from neutral to acidic without recovery problems. Retention times are predictable based on the monosaccharide composition of the glycans. Although chromatographic resolution is modest with respect to GCC and RPIP, the mobile phases are directly compatible with mass spectrometry.

\section{Capillary electrophoresis of glycoproteins and released glycans}

Developments in capillary electrophoresis (CE)/MS of glycans have been reviewed recently (Campa et al., 2006; Mechref and Novotny, 2006, 2009). Acidic glycans may be analyzed directly using CE or reductively aminated using an uncharged chromophore or fluorophore (Che et al., 1999; Militsopoulou et al., 2002). Neutral glycans may be reductively aminated with a sulfated derivative such as aminopyrene trisulfonate (Evangelista et al., 1995; Suzuki et al., 1997) or aminonapthalene trisulfonate (Klockow et al., 1995) to enhance their electrophoretic mobility. The advantages of $\mathrm{CE}$ are the high resolution separations, low sample consumption, and rapid analysis.

Negatively charged glycans may be analyzed directly by $\mathrm{CE} / \mathrm{MS}$ using polyvinylalcohol coated capillaries and neutral glycans may be analyzed following derivatization with aminonaphthalene trisulfonate (Gennaro et al., 2002). Glycosaminoglycan oligosaccharides are readily amenable to $\mathrm{CE}$ separation with MS detection due to their acidic character (Zamfir et al., 2002, 2004). An alternative to use of reductively aminated derivatives has been published in which $N$-glycans released by peptide $\mathrm{N}$-glycosidase $\mathrm{F}$ are derivatized with 9-fluorenylmethyl chloroformate using the reactivity of the reducing end glycosyl amine using a commercial neutral coated capillary (Nakano et al., 2009). The method was applied to the analysis of glycoproteins from SDS-PAGE bands using in-gel digestion with peptide $N$-glycosidase F followed by in situ derivatization prior to CE/MS.

The following is a summary of recent CE/MS applications to glycoprotein analysis. Polyvinyl alcohol-coated capillaries have been used to analyze glycopeptides from recombinant protein proteolytic digests (Gennaro et al., 2006). Released glycans were then analyzed by CE/MS of the APTS derivatives (Gennaro and Salas-Solano, 2008). The glycopeptide CE/MS data prove very useful for mapping $N$ - and $\mathrm{O}$-glycosylation sites in recombinant glycoprotein molecules. A method of analysis of intact recombinant glycoproteins has been developed using polybrene-coated capillaries to minimize the electroosmotic flow (Balaguer et al., 2006). The results show baseline electrophoretic separation of sialylation variants of erythropoietin and $\alpha_{1}$ acid glycoprotein (Balaguer and Neususs, 2006) with high-resolution mass spectrometric detection. The CE/MS method may also be used for analysis of released glycans from the recombinant glycoproteins. Polyvinylalcohol coated capillaries have been used for glycoprotein CE coupled to a high-resolution Fourier transform mass spectrometer for high mass accuracy glycoprotein analysis (Thakur et al., 2009). The method enabled identification of more than 60 glycoforms for recombinant human chorionic gonadotrophin. Subsequent analysis of tryptic peptides enabled identification of site-specific glycan variants.

\section{Ion mobility MS applied to glycomics}

Glycans released from glycoconjugates exist as mixtures of nonisomeric and isomeric glycoforms. Gas phase ion mobility separates ions according to their collisional crosssections, roughly proportional to the molecular size and shape (Clowers and Hill, 2005; Clowers et al., 2005). In principle, differences in ion mobility may be used to separate structural isomers, provided that the isomers have significantly different collisional cross sections. Ion mobility separations are also used as a separation dimension prior to mass spectrometric analysis. Seen in this way, the mobility separation helps resolve complex molecular mixtures. This capability may be of use when applied to glycomics of complex mixtures.

Ambient pressure ion mobility has been used with a TOF analyzer to resolve isomeric methyl glycosides and simple sugars differing by anomeric configuration (Dwivedi et al., 2007). Ion mobility spectrometry (IMS) has been applied to the identification of candidate biomarkers from permethylated $\mathrm{N}$-glycans released from serum samples liver cancer, cirrhosis, and control human patient populations (Isailovic et al., 2008). In this case, the permethylated glycans were analyzed by direct infusion without prior chromatographic separation. The data were reduced using statistical plots and clustered the patterns of glycan expression into groups correlating with disease state. IMS has been used to resolve heparan sulfate isomers from hexasaccharides purified by size-exclusion chromatography followed by strong anion exchange chromatography (Sche- 
nauer et al., 2009). Two of the SAX peaks had the same mass values but showed differences in product ion abundances likely to reflect different structures. The two hexasaccharide fractions showed ion mobility distributions, the peak centers of which differed significantly. Subsequent one dimensional ${ }^{1} \mathrm{H}$-nuclear magnetic resonance spectroscopy indicated that the differences were due to uronic acid epimerization.

\section{Mass spectrometry of high molecular weight glycoconjugates}

Mass spectrometric analysis of high molecular weight glycoconjugates is made challenging by both the comparative fragility of glycan chains and their heterogeneity. Thus, although MALDI produces low charge states that are readily interpretable, glycans often undergo fragmentation during the ionization process. Permethylation renders glycans substantially more stable than the native molecules. The derivatization chemistry, however, entails dissolving the glycans in DMSO, a solvent in which polysaccharides have decreasing solubility with increasing size. Use of ESI is more likely to result in ionization without fragmentation. The ion patterns, however, may be extremely complex due to carbohydrate polymeric complexity and overlapping charge state envelops. These principles are shown in the analysis of a dextran 5000 polymeric mixture using ESI MS and MALDI-TOF MS (Deery et al., 2001). Comparable results on these polysaccharides were obtained using the two techniques for these neutral, relatively stable, polysaccharides.

The bioactive bacterial extracellular polysaccharide Curdlan has been analyzed in native form using MALDI-TOF MS to show a polymeric mixture ranging from 5,000-14,000 Da (Chan and Tang, 2003). The $O$-antigen from $F$. tularensis was permethylated and analyzed using MALDI-TOF mass spectrometry and showed a polymer consisting of a series of tetrasaccharide units attached to a core oligosaccharide of composition ( $\mathrm{HexNAc}_{3} \mathrm{Hex}$ )Kdo (Prior et al., 2003). Glycosaminoglycan polymers of up to degree of polymerization 40 have been observed using an LC/MS system employing reversed phase ion pairing chromatography (Kuberan et al., 2002). This system has the advantage that the complexity of the polysaccharides entering the MS source at a give time is limited by the chromatography system. A low molecular weight heparin preparation with average molecular weight of $\sim 5,500 \mathrm{Da}$ was analyzed using on-line SEC-MS (Henriksen et al., 2004). Again, the chromatography stage increases the extent to which the complex ion patterns may be interpreted. Hyaluronan oligosaccharides have been analyzed using MALDI-TOF MS (Sakai et al., 2007). This work that showed increases in sensitivity for oligomers ranging from dp 4-34 when uronic acid residues are derivatized to methyl esters. Nano-ESI FTMS has been used to analyze O-glycopeptides from the S-layer glycoprotein of Geobacillus stearothermophilus NRS 2004/3a (Bindila et al., 2007; Steiner et al., 2006). This approach identified a 12 amino acid peptide backbone with up to 51 monosaccharide residues.

\section{Mass Spectral Glycomics Profiling}

\section{Approaches without stable isotope labels}

$N$-linked glycomics. The recent Human Proteome Organization multi-institutional study of quantitative profiling of glycoprotein glycans highlights the strengths and weakness of methods that are used widely (Wada et al., 2007). Chromatographic quantitation results differed among laboratories due to differences in reductive amination methods used. Laboratories that used permethylation of the released $N$-glycans MS showed more consistent results. Determination of relative glycan quantities was most straightforward with the permethylation approach because of the chemical similarities of the derivatized glycans. The ESI LC/MS approach was soft enough so that sialylated glycans were not fragmented during ionization. The ionizations responses depended on the degree of sialylation, however, somewhat complicating the task of determining the quantitative results. Underivatized sialylated glycans tended to undergo in-source dissociation when analyzed using MALDI.

Permethylation both increases the ionization response and equalizes the chemical properties of glycans. Permethylation also renders the glycans stable enough so that they do not fragment in the MALDI source. MALDI-TOF MS has been used to differentially profile glycans expressed in the Caenorhabditis elegans model organism (Cipollo et al., 2002). The studies elucidated a five major $N$-glycan series (high mannose, hybrid, complex, fuco-pausimannosidic, and phosphocholine). This approach facilitated studies of phosphocholine $N$-glycan biosynthesis (Cipollo et al., 2004a) and the expression of $N$-glycans in C. elegans mutants (Cipollo et al., 2004b).

A solid-phase permethylation procedure (Kang et al., 2005) has been used to analyze $N$-linked glycan hepatocellular carcinoma biomarkers in serum using MALDI-TOF MS (Ressom et al., 2008). The released glycans were captured using reversed phase solid phase extraction prior to MALDI MS. A peak detection algorithm was developed for identification of hepatocellular carcinoma from a high-risk patient population using both glycan and peptide mass spectrometric data. A platform for graphtitized carbon on-line LC/MS has been developed to facilitate isomeric separation of permethylated glycans (Costello et al., 2007). Multistage tandem MS has been used to determine detailed permethylated glycan structures in metastatic and non-metastatic tumor cells (Prien et al., 2008). The multistage tandem MS approach has identified a series of unique nonreducing terminal trisaccharides that characterize the metastatic cells. The presence of such structures is observed only when the glycans are disassembled in the gas phase to enable formation of diagnostic crossring cleavages.

Other glycomics approaches target native $N$-glycans. For this purpose, steps must be taken to stabilize or remove sialic acid residues if MALDI is to be used as the ionization method. For example, a chemoselective glycoblotting technology has been developed to capture enzymatically released glycans from serum using immobilized hydrazide chemistry (Furukawa et al., 2008). The immobilized glycans were methyl esterified while immobilized and then released and analyzed by MALDI-TOF MS. The technique was used to profile $N$-glycans from purified glycoproteins and from ascites and pleural fluids.

A two-dimensional chromatography system has been developed to map $N$-glycans followed by MALDI TOF/TOF structural analysis (Hato et al., 2006). The released glycans were first fractionated by size exclusion chromatography, reductively aminated with aminopyridine, and then fractionated using amide hydrophilic interaction chromatography. 
Glycans were enzymatically desialylated and then analyzed using MALDI TOF/TOF. The glycans were analyzed in both a cool matrix (dihydrozybenzoic acid) and a hot matrix $(\alpha$-cyano-4-hydroxybenzoic acid) to increase the production of structurally informative product ions.

O-linked glycomics. The characterization of neutral oligosaccharide alditols released from Xenopus laevis egg jelly coats (Tseng et al., 1997) led to the definition of a catalog library approach for characterization of sub-structural motifs (Tseng et al., 1999). Using this approach, product ion signature patterns determine the presence of known substructures in related oligosaccharide molecules (Tseng et al., 2001). The catalog library approach has also been used with exoglycosidase digestion to identify the linkages of individual residues (Zhang et al., 2004a). An LC/MS approach has also been used to profile the morphological distribution of O-linked oligosaccharides in distinct jelly coat layers in Xenopus laevis (Zhang et al., 2004b).

Mucin oligosaccharides have high value as potential disease biomarkers. Mucin O-glycans have been profiled from gastric biopsies of Rhesus monkeys as a function of Helicobacter pylori infection (Cooke et al., 2007). The O-glycans released by $\beta$-elimination were profiled by ESI and MALDI Fourier transform MS (FTMS). Unsupervised cluster analysis was used to demonstrate differences between the two sample populations. The data demonstrate that core structures with compositions HexNAcHex and $\mathrm{HexNAc}_{2}$ to be absent in the infected population. An approach for serum glycomics for breast cancer biomarkers has been developed using released O-glycans from cancer cell lines and serum samples (Kirmiz et al., 2007). The compositions of the unfractionated released glycans were compared for the sample sets from the MALDI FT mass spectra. Principle component analysis was used to group human serum samples according to cancer status. Structural analysis was carried out using infrared multiphoton dissociation (IRMPD).

The glycan profiles of mucin oligosaccharides are instructive for glycomics efforts in general. A significant fraction of the structures are sulfated and therefore not compatible with permethylation. In native or reductively aminated forms, they are likely to undergo a significant degree of fragmentation during MALDI ionization. Use of ESI-based methods has advantages for sulfated compound classes because the low degree of in-source fragmentation observed. An on-line graphitized carbon LC/MS has been developed with negative ion ESI (Karlsson et al., 2004). This approach has been used for analysis of glycosylation of sputum mucins in cystic fibrosis patients (Schulz et al., 2007). Glycoproteins from sputum were separated by gel electrophoresis and blotted onto membranes, and stained with Alcian Blue. Glycans were released from stained protein bands by reductive $\beta$-elimination and analyzed by graphitized carbon ESI LC/MS. Clear differences in glycan structures were observed between cystic fibrosis patients and healthy controls. These differences included increased abundances of specific structures in the cystic fibrosis patients, including Lewis and other fucosylated and sialylated epitopes that may serve as high affinity epitopes for bacteria.

A device has been developed for rapid nonreductive alkaline $\beta$-elimination of $O$-glycans for subsequent reductive amination and mass spectral or chromatographic analysis (Matsuno et al., 2007). Glycoproteins are injected into a flow stream and reacted for $3 \mathrm{~min}$ to achieve recovery of reducing $\mathrm{O}$-glycans without peeling. A cation exchange resin is used to rapidly neutralize the solution following reaction. This device has been applied to the analysis of mucin oligosaccharides in conjunction with reductive amination and MALDI-TOF MS (Yamada et al., 2007). Released glycans were detected from as low as 5 pmol starting glycoprotein.

Human milk glycomics. Studies of glycans derived from milk have been of long standing interest (Kunz et al., 2000) and mass spectrometry has played a pivotal role in these efforts (Bruntz et al., 1988; Dreisewerd et al., 2006; Stahl et al., 1994). It is now widely appreciated that human milk contains a far higher concentration of complex oligosaccharides than do most other species. Recently, high-performance thin layer chromatography has been applied to comparative profiling of elephant and human milk samples (Dreisewerd et al., 2006). These studies demonstrate the potential of tandem MS for comparison glycan expression in complex biological samples.

A strategy for quantitative profiling of the human milk glycome has been described in which glycans are analyzed using on-line chip-based porous graphitized carbon LC/MS using a QTOF instrument (Ninonuevo et al., 2006). The MS dimension serves to define the compositions and abundances of milk oligosaccharide alditols in each of a series of human milk samples. A combination of IRMPD FTMS and exoglycosidase digestion were used to determine structural details on targeted milk glycan alditols. This method has been used to study the consumption of milk oligosaccharides by bifidobacteria (LoCascio et al., 2007) and daily variations in oligosaccharides present in human milk (Ninonuevo et al., 2008).

\section{Stable isotope labels for glycomics}

Permethylation labeling. Permethylation using deuterated methyl iodide has been used to introduce a stable isotope label for quantitative purposes (Viseux et al., 1999). For such labels, the mass shift varies according to the glycan composition. A comparative glycoform mapping method (C-GlycoMAP) has been developed based on differential stable isotope labeling $\left(\mathrm{CH}_{3} \mathrm{I} / \mathrm{CD}_{3} \mathrm{I}\right)$ and permethylation (Kang et al., 2007). Reliable comparisons were obtained when intensity ratios were between 0.125 and 6 and the overall reproducibility was better than $30 \%$ relative standard deviation. Tandem MS has been used to gain additional structural information on differential stable isotope labeled glycans in such MALDI mass spectra. The method was also shown to be applicable to $\mathrm{O}$-glycans. Stable isotope labels have also been introduced using ${ }^{13} \mathrm{CH}_{3} \mathrm{I}$ (Alvarez-Manilla et al., 2007; Aoki et al., 2007). Released $\mathrm{N}$-glycan mixtures were differentially labeled with ${ }^{12} \mathrm{C}$ or ${ }^{13} \mathrm{C}$ forms of the permethylation reagent and profiled using positive ion MALDI TOF MS and ESI FTMS. Relative quantification was effective over two orders of magnitude in mixture ratio and coefficients of variation ranging from 15-25\% were reported (Alvarez-Manilla et al., 2007).

Use of an internal standard is a means to compensate for subtle differences in MS ionization among analytes and for compensating for changes in instrumental performance over time. The chemical properties of the internal standard should be the same as the analyte in question and thus stable isotope labels are often used for this purpose. One limitation to the use 
of $\mathrm{CD}_{3}$-methylated or ${ }^{13} \mathrm{CH}_{3}$-methylated labels is that the mass difference varies according to the glycan composition. The use of tandem mass spectrometric dissociation for comparison of isomeric mixture compositions among different samples is best accomplished when both the heavy and light isotopic forms may be isolated simultaneously. This is generally not possible for the relatively large mass differences obtained with the above permethylation labels.

It is also possible to quantify glycans using stable isotope labels that have the same nominal mass but different exact mass (Atwood et al., 2008). Such labels have been introduced by permethylation using ${ }^{13} \mathrm{CH}_{3} \mathrm{I}$ versus $\mathrm{CH}_{2} \mathrm{DI}$, differing in mass by $0.002922 \mathrm{Da}$. It is possible to resolve permethylated $N$-glycans modified with these variants using a mass spectrometer with greater than 30,000 resolution, such as are becoming increasingly common in today's market. This approach has the advantage that glycans labeled with heavy and light forms may be mixed and subjected to tandem mass spectrometry using narrow precursor ion isolation conditions.

Reductive amination. Commercially available amine compounds available in stable isotope-labeled form are appropriate for incorporation of stable isotope labels into glycans using reductive amination chemistry (Hitchcock et al., 2006a; Yuan et al., 2005). Deuterated anthranilic acid $\left(d_{4}\right)$ has been used for quantitative studies on the expression of chondroitin/dermatan sulfate in connective tissue using LC/MS and LC/tandem MS (Hitchcock et al., 2006a, 2006b, 2008). A similar approach using deuterated pyridyl amine has been used with graphitized carbond LC/MS for quantification of $\mathrm{N}$-glycans (Yuan et al., 2005). Deuterated tags have the potential disadvantage that they are resolved by some chromatography systems. To overcome this, ${ }^{13} \mathrm{C}_{6}$-aniline-based tags have been developed and applied to profiling of GAGs from several species (Lawrence et al., 2008). This tag has the additional advantage of larger spacing between heavy and light forms. A tetraplex deuterated tag has been developed and applied to mass spectrometric quantification of GAG oligosaccharides. This approach enables the simultaneous analysis of four glycan samples using the $d_{0}, d_{4}, d_{8}$ and $d_{12}$ forms of the tags, respectively.

\section{Tandem MS and the Analysis of Isomeric Glycan Mixtures}

The following discussion will use the well-known nomenclature for glycoconjugate tandem mass spectrometric product ions (Domon and Costello, 1988a). Cleavage of the glycan chain occurs by rupture of glycosidic bonds (B, C, X, Y types) or across rings ( $A$ and $X$ types). Product ion containing the original nonreducing oligosaccharide end are A, B, and C types, and those containing the original reducing end or aglycon are $\mathrm{X}, \mathrm{Y}$, and $\mathrm{Z}$ types.

Permethylation of glycans has particular advantages for tandem mass spectrometric structural analysis because all glycan $\mathrm{OH}$ and $\mathrm{NH}$ groups are derivatized. As a result, glycan bond scission occurring during tandem MS creates unmodified sites, commonly called "scars," the presence of which indicate which bond has been cleaved. The linkage position for a given monosaccharide is therefore indicated by the masses of the crossring cleavage ions (A or X types). Likewise, crossring cleavage ion masses are useful for determining the linkages and masses of substituents that modify branched monosaccharide residues. These principles have been developed into a strategy for determination of glycan linkage and branching structure (Ashline et al., 2005). This strategy involves multiple stages of dissociation of the glycan to produce substructures of approximately disaccharide size in the gas phase that produce readily interpretable product ion patterns (Lapadula et al., 2005; Zhang et al., 2005). A single stage of tandem mass spectrometry produces less information than multistage tandem MS but can be accomplished more rapidly and on a smaller sample quantity (Costello et al., 2007).

Tandem mass spectra of native and reductively aminated glycans produce less definitive structural information because the glycosidic bonds cleaved during dissociation do not leave a mass scar. Thus, it is only possible to determine residue linkage sites when a crossring cleavage is observed to that residue in which the substituents remain intact. Balancing this, not all glycan classes are readily amenable to permethylation, and are thus more appropriate for analysis in native or reductively aminated form.

\section{Lactosamine linkages}

In positive ion mode, native and reductively aminated glycans form abundant product ions from cleavages adjacent to NeuAc, HexNAc, and Fuc residues. Crossring cleavages to branching residues are typically low in abundances. Type 1 and type 2 chains differ in the $N$-acetyllactosamine linkage and may be differentiated based on the product ions using negative mode collisional-activated dissociation (CAD). HexNAc residues with four linkages undergo facile A-type cleavage. The formation of such A-ions is blocked for the three-linked residues, and a D-ion is formed from combined $\mathrm{C} / \mathrm{Z}$ cleavages (Chai et al., 2001; Pfenninger et al., 2002a, 2002b).

\section{Sialic acid linkage isomers}

Sialic acid linkages may be differentiated from positive ion CAD of transition metal complexes (Leavell and Leary, 2001). Such linkages may also be differentiated in the negative mode using $\mathrm{MS}^{2}$ of deprotonated ions in which an ion corresponding to ${ }^{0,4} \mathrm{~A}_{4}-\mathrm{CO}_{2}$ correlates with an $\alpha 2,6$ isomer (Wheeler and Harvey, 2000). In addition, an $\mathrm{MS}^{\mathrm{n}}$ series may be used to differentiate sialic acid linkages by dissociation of C- or D-ions (Deguchi et al., 2006b; Ito et al., 2007). For permethylated glycans, the masses of specific A-type ions occurring to the Gal residue to which NeuAc is attached differentiate $\alpha 2,3$ and $\alpha 2,6$ linkages (Lemoine et al., 1991, 1993). These fragment ions have been used to differentiate sialic acid linkages using modern MALDI TOF/TOF instruments (Mechref et al., 2006).

\section{Branching isomers}

The determination of the glycan branching structure using tandem MS entails the observation of crossring cleavage or D-type ions occurring about the branching residue. Native or reductively aminated glycans observed as sodiated precursor ions dissociate to form A-type ions to the core branching mannose residue of $N$-glycans that may be used to determine the compositions of the three and six branches (Harvey, 2000a, $2000 \mathrm{~b})$. Such ions are often observed in increasing abundances for deprotonated precursor ions in the negative mode, as has 
been observed for branched milk oligosaccharides (Chai et al., 2002) and $N$-glycans (Harvey, 2005a, 2005b, 2005c). The formation of the D-ion is particularly useful since it occurs only for three-linked residues.

Electron detachment dissociation (EDD) of native glycans has been shown to produce tandem mass spectrometric patterns that are particularly useful for deriving structural information (Adamson and Hakansson, 2007). Sialylated glycans produce abundant negatively charged precursor ions and, in contrast to CAD, do not undergo facile losses of acidic residues. Product ions of types B, C, Y, and Z are observed for most glycosidic bonds in $\mathrm{N}$-glycans and an abundance of A- and X-type crossring cleavages are observed.

Tandem MS of permethylated glycans carries the advantage that ions formed from cleavage of glycosidic bonds have a unique mass value that distinguishes an internal fragment from a single bond cleavage. Single-stage tandem MS of permethylated glycans is a well-established approach for determining overall branching structure (Domon and Costello, 1988b) and some structural isomers (Mechref et al., 2006). A single stage of dissociation gives rise to abundant B- and Y- type ions. A-type crossring cleavages are often abundant, and serve to define the compositions of antennae when they occur to branching residues. Multistage dissociation of permethylated glycans has been used to determine detailed linkage information for disaccharide units formed by gas phase disassembly of the glycans (Ashline et al., 2005; Lapadula et al., 2005; Sheeley and Reinhold, 1998; Zhang et al., 2005). The key to multistage dissociation of glycans is the selection of a series of precursor ions that isolate structural branches for subsequent stages of dissociation. Subsequent dissociation of B-type ions yields crossring cleavages that are useful for determining linkage. Permethylated glycans may also be subjected to high energy ECD, under which dissociation conditions complementary product ions are formed (Zhao et al., 2008). High-energy ECD results in dominant Cand Z-type glycosidic cleavage with complementary A- and $X$-type crossring cleavages.

\section{Fucosylated isomers}

Determination of fucose positional isomers is a key issue in the analysis of glycans bearing blood-group related determinants and Lewis structures. For native or reductively aminated glycans in the positive mode, the observation of glycosidic cleavages (B- and Y-ions) often suffices to determine whether fucosylation is present on the antennae versus the core (Suzuki et al., 2005; Vakhrushev et al., 2004). Likewise, in the negative mode, $\mathrm{C}_{-}, \mathrm{A}-$, and $\mathrm{D}$-ions may be used to differentiate fucosylation isomers (Harvey et al., 2008; Sagi et al., 2002). For permethylated glycans, fucosylation isomers may be differentiated based on a combination of B-, Y-, and A-type ions (Viseux et al., 1997).

\section{Determination of other disaccharide linkages}

In the process of disassembly of glycans in the gas phase, the amount of information produced on individual structural elements increases. The formation of B-type ions from dissociation of permethylated glycans in a trapped ion instrument has the advantage that subsequent crossring cleavages are favored through retro-Diels Alder rearrangement. Such frag- mentation has been shown to differentiate $\mathrm{Gal} \alpha(1-4) \mathrm{Gal} \beta$ (1-4)Glc-ol from Glc $\alpha(1-4)$ Glc $\alpha(1-4)$ Glc-ol using $\mathrm{MS}^{3}$ of the $\mathrm{B}_{2}$ ion. This general approach has been applied to analysis of $\mathrm{N}$ - and O-glycans (Anthony et al., 2008; Hanneman et al., 2006; Lapadula et al., 2005; Prien et al., 2008; Zhang et al., 2005). The multistage tandem MS approach necessitates extended data acquisition times and is therefore applicable to either MALDI or infusion-based ESI approaches. On-line LC/MS approaches are not likely to permit such extended data acquisition (Ashline et al., 2007).

\section{Glycosaminoglycan isomers}

MS of glycosaminoglycans has been reviewed (Zaia, 2005). Heparan sulfate and chondroitin sulfate glycosaminoglycans are expressed as domains of high and low degrees of sulfation (Esko and Selleck, 2002). The patterns of modification of the nascent carbohydrate chain determine their biological activities with respect to binding of protein partners (Kreuger et al., 2006). Glycosaminoglycans are readily depolymerized into their constituent disaccharide repeats using polysaccharide lyases (Ernst et al., 1995), the compositions of which mixtures indicate the bulk properties of the parent chains. Such disaccharides ionize readily using negative ion ESI MS, and the tandem mass spectrometric product ion abundances may be used to quantify disaccharides produced by enzymatic digestion (Behr et al., 2005; Desaire and Leary, 2000; Desaire et al., 2001; Saad and Leary, 2003; Saad et al., 2005). Extended glycosaminoglycan chains may be produced by reducing the polysaccharide lyase digestion stringency. Negative ion ESI tandem MS may be used to differentiate the structural isomers present in chondroitin sulfate mixtures based on the abundances of diagnostic product ions using native (McClellan et al., 2002; Miller et al., 2006; Zaia et al., 2001) or reductively aminated glycans (Hitchcock et al., 2006a, 2006b, 2008; Zaia et al., 2003).

EDD has also been applied to the analysis of glycosaminoglycan oligosaccharides (Chi et al., 2008; Wolff et al., 2007a, 2007b). Product ions were observed that were diagnostic for uronic acid epimerization state, a particularly important question in glycosaminoglycan structural biochemistry.

\section{MS of Glycopeptides}

Enrichment approaches for glycoproteomics have been reviewed recently (Wuhrer et al., 2007a; Xin et al., 2008) and a few will be summarized here. Immobilized lectin may be used to enrich glycoproteins or glycopeptides (Cummings, 1994; Cummings and Kornfeld, 1982; Hirabayashi, 2008) for subsequent MS analysis (Madera et al., 2005; Patwa et al., 2006; Qiu and Regnier, 2005; Yang et al., 2005). Glycopeptides may also be isolated by hydrophilic interaction solid phase extraction (Wada et al., 2004) or chromatography (Wuhrer et al., 2005b) and graphitized carbon solid phase extraction (Larsen et al., 2005). They may be enriched based their high molecular weight using size exclusion chromatography (Alvarez-Manilla et al., 2006) or captured by binding to immobilized boronic acid derivatives (Sparbier et al., 2005).

The simplest approach to analysis of the enriched glycoproteins or glycopeptides is to deglycosylate and to do proteomic identification of the sites of occupancy (Qiu and Regnier, 2005; Xiong et al., 2003). Enzymatic release of 
$N$-glycans converts glycosylated Asn residues to Asp. The resultant mass difference can be used to determine sites of $\mathrm{N}$-glycosylation, provided that intrinsic rates of Asn deamidation are taken into account. Release of $\mathrm{N}$-glycans in $\mathrm{H}_{2}{ }^{18} \mathrm{O}$ distinguishes the site of occupancy from an Asp produced by deamidation and has been used in glycoproteomics work flows (Kaji et al., 2003). Care must be taken to avoid spurious incorporation of ${ }^{18} \mathrm{O}$ into peptide C-termini through residual trypsin activity (Angel et al., 2007). A multiple reaction monitoring method has been developed to quantify ${ }^{18} \mathrm{O}$-labeled peptides from selected serum glycoproteins to assess the correlation of $N$-linked site occupancy with severity of congenital disorders of glycosylation (Hulsmeier et al., 2007).

Isotope-coded glycosylation-specific tagging (IGOT) is based on the incorporation ${ }^{18} \mathrm{O}$ at the site of $\mathrm{N}$-glycosylation in a proteomics workflow (Kaji et al., 2003; Kaji et al., 2007). Glycoproteins are enriched from a complex mixture using lectin affinity chromatography. The glycoproteins are digested with trypsin and the resultant glycopeptides enriched by repeating the lectin affinity step. The glycopeptides are then digested with PNGase $\mathrm{F}$ in the presence of $\mathrm{H}_{2}{ }^{18} \mathrm{O}$, labeling the sites of $\mathrm{N}$-glycosylation and analyzed using a twodimensional LC/MS/MS proteomics workflow. This method has been applied to analysis of $N$-glycans in the C. elegans nematode.

Another approach entails oxidation of glycoprotein using periodate. This reaction converts cis-diols on carbohydrates to aldehydes. The glycoproteins containing oxidized carbohydrates are then coupled to a solid support using hydrazide chemistry (Tian et al., 2007; Zhang et al., 2003). Nonglycosylated proteins are washed away. The bound proteins are then digested with trypsin and analyzed using MS-based proteomics to identify the glycoprotein. This approach has been used to capture glycoproteins from serum and showed increased efficiency of glycoprotein identification compared with a proteomics workflow that did not use an enrichment step. This method does not identify directly the site of glycosylation.

Several groups have published workflows for serum glycoproteomics based on use of lectins for affinity capture of glycoproteins or glycopeptides (Geng et al., 2001). Serial lectin affinity chromatography has been used to affinity enrich glycopeptides (Geng et al., 2001) from tryptic digests of serum (Qiu and Regnier, 2005). The bound and unbound fractions are differentially stable isotope labeled using an aminespecific tag (Chakraborty and Regnier, 2002). The fractions are then mixed, deglycosylated, and analyzed using MS-based proteomics. The results show the class of $N$-glycan based on the known selectivity of the lectin(s) used.

Multiple lectin affinity chromatography entails use of a single column with three lectins (ConA, WGA, and jacalin) to achieve binding for a broad range of glycan structures (Wang et al., 2006; Yang et al., 2005). The affinity enriched glycoproteins are digested with trypsin and analyzed using MS-based proteomics. This approach has been used in conjunction with abundant protein depletion for analysis of glycoprotein biomarkers in serum (Plavina et al., 2007). Silicabased lectin microcolumns have been developed that improved the binding capacity, trapping reproducibility, and substrate selectivity over agarose-based materials (Madera et al., 2005). These microcolumns have been used in a workflow in which enriched glycoproteins are fractionated using high-temperature reversed-phase HPLC, followed by trypsinization and LC/MS analysis of the resultant peptides (Madera et al., 2006). The results compare the distribution of glycoproteins identified from serum using different lectins.

To gain information on the glycan structures modifying individual amino acid residues, it is necessary to analyze the glycopeptide directly. One approach is to digest the glycoprotein with a nonspecific protease, generating glycopeptides bound to very small peptides (An et al., 2003). A computer program has been developed to determine the amino acid site of occupancy and the glycosylation microheterogeneity at each site (An et al., 2006). Another approach combines MS and tandem MS data obtained on glycoprotein tryptic digests to identify sites of glycan occupancy and microheterogeneity (Goldberg et al., 2007). This approach leverages careful recalibration of Q-TOF data using known peptides to maximize mass accuracy and certainty of assignment.

\section{Tandem MS of Glycopeptides}

Tandem MS for glycoproteomics has been reviewed recently (Wuhrer et al., 2007a). One of the challenges to glycopeptidomics is that the glycan moiety has different chemical properties than the peptide backbone and dissociates under different mass spectrometric conditions.

\section{Collision-induced dissociation and infrared multiphoton dissociation}

Dissociation of glycopeptides using CAD or IRMPD tends to produce abundant ions from cleavage of glycosidic bonds and low abundance ions from peptide backbone scission (Wuhrer et al., 2007a). The balance of glycosidic versus peptide backbone dissociation types depends on the glycopeptides structure. In particular, high mannose $N$-glycans do not undergo glycosidic bond cleavage as readily as complex $N$-glycans, and produce relatively abundant ions from peptide backbone cleavage using IRMPD (Adamson and Hakansson, 2006). The balance of fragmentation observed by CAD also depends on the mass analyzer used. Trapped ion instruments dissociate only a selected $\mathrm{m} / \mathrm{z}$ window. As a result, product ions are no longer excited, and the extent of fragmentation is low. This can be a disadvantage for glycopeptides since glycosidic bonds dissociate most readily. The extent of dissociation for glycopeptides is often higher for QTOF type instruments in which a beam of ions are passed through a collision cell. Product ions may continue to fragment, generating a greater diversity of product ions in an single stage of dissociation. Thus, it is possible to increase the extent of peptide backbone fragmentation by increasing the collision energy. A useful experiment is therefore to acquire the positive ion tandem MS at low energy for glycan fragmentation and higher energy for peptide backbone fragmentation.

Recently, the influence of charge state and cationization form on IRMPD product ion pattern has been investigated for a series of glycopeptides generated from pronase digestion of glycoproteins (Seipert et al., 2008). The glycans were neutral, primarily high mannose $N$-glycan type. Singly protonated glycopeptide ions with a peptide containing a basic residue 
dissociated to form abundant ions from peptide backbone cleavage. Multiply protonated ions for such glycopeptides dissociated primarily through glycosidic bond cleavages. Glycopeptides without basic amino acids dissociated primarily through glycosidic cleavage regardless of protonated charge state. Sodium-cationized glycopeptides dissociated primarily through glycosidic cleavages. These results are consistent with the observations made by researchers seeking to combine ECD and CAD or ECD and IRMPD, in which multiply protonated precursor ions are necessary.

\section{Electron capture dissociation (ECD)}

ECD selectively fragments the peptide backbone of glycopeptides, allowing the site of glycosylation to be determined (Håkansson et al., 2001). IRMPD and CAD, by contrast, tend to produce abundant glycosidic bond cleavages for glycopeptides (Wuhrer et al., 2007a). Thus, a combination of ECD/ETD and dissociation based on increasing internal bond energy (CID or IRMPD) produces the greatest amount of information on the glycopeptide structure. Commercial mass spectrometers (ion trap and hybrid ion trap-FTMS) are available with these capabilities. The use of ECD and IRMPD have been reported for a xylosylated neutral $\mathrm{N}$-linked glycopeptide (Håkansson et al., 2001; Hakansson et al., 2003) and high mannose $N$-linked glycopeptides (Adamson and Hakansson, 2006). The modification site and glycan mass was determine for a monosialylated $N$-linked glycopeptide that also carried an $O$-glycosylation site (Kjeldsen et al., 2003).

ECD has been used effectively to determine sites of occupancy for glycopeptides bearing several sites of O-glycosylation (Kjeldsen et al., 2003; Renfrow et al., 2005, 2007). ECD in a linear ion trap MS (Baba et al., 2004) has been proposed in conjunction with negative ion CAD as a means of complete glycopeptides analysis (Deguchi et al., 2007). The advantage to the use of the negative mode for CAD is that C-ions are abundant, from which A-type crossring cleavage ions are formed. Thus, the CAD product ion profiles of the glycan moiety are highly informative (Deguchi et al., 2006a).

Beyond these examples, there do not appear to be any reports demonstrating the incorporation of ECD into an applied $N$-glycan glycoproteomics work flow. There are only a few reports showing ECD of sialylated glycopeptides (Deguchi et al., 2007; Kjeldsen et al., 2003).

\section{Electron transfer dissociation}

The capability of electron transfer dissociation (ETD) in an ion trap instrument has been demonstrated using the same glycopeptide use with earlier ECD work (Hogan et al., 2005). This glycopeptide has a composition of GlcNAc ${ }_{2} \mathrm{Man}_{3} \mathrm{FucX}_{\mathrm{C}}$. It is xylosylated at the core branching mannose and fucosylated at the GlcNAc residue bound to the peptide, and derives from a plant lectin. The dissociation pattern generated by ETD showed a series of c- and z-type product ions from peptide backbone dissociation that defined the site of glycosylation and the mass of the glycan. CAD of the glycopeptide produced a series of ions from loss of monosaccharide residues from the nonreducing termini. A similar series of plant glycopeptides, containing xylosylated and fucosylated chitobiose structures, were analyzed using on-line LC/MS with a combination of ETD and CAD dissociation (Hogan et al., 2005). The ETD step produced a series of c- and z-type pep- tide backbone fragments and glycosidic cleavages to a lesser extent. A combination of ETD and CAD has been used for on-line LC/MS of a high mannose $N$-glycosylated peptide from human epidermal growth factor receptor ( $\mathrm{Wu}$ et al., 2007). The CAD stage resulted in a series of losses of Man residues. The ETD stage showed peptide backbone dissociation of the 36-esidue peptide backbone, with limited coverage. Increased peptide backbone coverage was obtained by CAD $\mathrm{MS}^{3}$ of the charge-reduced ion from the ETD MS ${ }^{2}$ stage. The glycan was attached to the amino-terminal residue, and only z-type peptide product ions were observed. Complex immunoglobulin $N$-glycopeptides from human serum have been analyzed by nano-LC/MS with a combination of CAD and ETD dissociation (Wuhrer et al., 2007b). A nonapeptide with Asn are position 5 and an $\mathrm{N}$-glycan of composition $\mathrm{HexNAc}_{4} \mathrm{Hex}_{3} \mathrm{dHex}$ dissociated by CAD to produce a series of ions from loss of monosaccharide units from the nonreducing glycan ends. ETD of the $[\mathrm{M}+2 \mathrm{H}]^{2+}$ ion showed a series of $z$-type peptide backbone product ions that defined the site of modification and mass of the glycan. No ETD spectra were shown for sialylated glycopeptides.

At the time of this writing, glycoproteomic workflows incorporating on-line LC/MS with a combination of ETD and CAD have been demonstrated (Catalina et al., 2007; Wu et al., 2007; Wuhrer et al., 2007b). ETD has been shown only for neutral $\mathrm{N}$-glycopeptides (high mannose and asialocomplex).

\section{Conclusions}

Whether the concern is complete structural determination of a high value purified or synthetic glycan target, glycomics target discovery, basic scientific investigation, or commercial product development, mass spectrometry is an essential analytical tool. MALDI, with its ease of analysis of glycans from surfaces, and ESI, with its many applications with on-line chromatography, are complementary ionization methods applied to glycan analysis. Either ionization method may be applied to analysis of permethylated glycans. This derivatization is useful for stabilizing the glycans, increasing ionization responses, and for producing very useful product ion patterns. Reductive amination of glycans adds chemical functionality and is compatible with MS. Analysis of native glycans is preferred when available quantities do not permit derivatization. Reductively aminated and native glycans are best analyzed either as sodium cation or deprotonated anions for the purpose of generating useful tandem mass spectra. Tandem mass spectrometry may be used to determine linkage details from multistage dissociation studies, or general patterns of branching when employed using a single stage of dissociation. It has been the intent of this review to orient the reader to the principles of glycan MS as appropriate for this compound class.

\section{Acknowledgments}

The author's effort is supported by NIH/NCRR grant P41RR10888 and NIH/NHLBI contract N01HV28178.

\section{Author Disclosure Statement}

The author declares that no conflicting financial interests exist. 


\section{List of Abbreviations Used}

CAD collisional-activated dissociation

ECD electron capture dissociation

EDD electron detachment dissociation

ETD electron transfer dissociation

ESI electrospray ionization

FTMS Fourier transform mass spectrometry

IRMPD Infrared multiphoton dissociation

LC/MS liquid chromatography/mass spectrometry

MALDI matrix-assisted laser desorption/ionization

MS mass spectrometry

QIT quadrupole ion trap

QQQ triple quadrupole

QTOF quadrupole time-of-flight

\section{References}

Adamson, J.T., and Hakansson, K. (2006). Infrared multiphoton dissociation and electron capture dissociation of highmannose type glycopeptides. J Proteome Res 5, 493-501.

Adamson, J.T., and Hakansson, K. (2007). Electron detachment dissociation of neutral and sialylated oligosaccharides. J Am Soc Mass Spectrom 18, 2162-2172.

Alvarez-Manilla, G., Atwood, J., III, Guo, Y., Warren, N.L., Orlando, R., and Pierce, M. (2006). Tools for glycoproteomic analysis: size exclusion chromatography facilitates identification of tryptic glycopeptides with N-linked glycosylation sites. J Proteome Res 5, 701-708.

Alvarez-Manilla, G., Warren, N.L., Abney, T., Atwood, J., III, Azadi, P., York, W.S., et al. (2007). Tools for glycomics: relative quantitation of glycans by isotopic permethylation using ${ }^{13} \mathrm{CH}_{3} \mathrm{I}$. Glycobiology 17, 677-687.

An, H.J., Peavy, T.R., Hedrick, J.L., and Lebrilla, C.B. (2003). Determination of $\mathrm{N}$-glycosylation sites and site heterogeneity in glycoproteins. Anal Chem.75, 5628-5637.

An, H.J., Tillinghast, J.S., Woodruff, D.L., Rocke, D.M., and Lebrilla, C.B. (2006). A new computer program (GlycoX) to determine simultaneously the glycosylation sites and oligosaccharide heterogeneity of glycoproteins. J Proteome Res 5, 2800-2808.

Angel, P.M., Lim, J.M., Wells, L., Bergmann, C., and Orlando, R. (2007). A potential pitfall in ${ }^{18} \mathrm{O}$-based $N$-linked glycosylation site mapping. Rapid Commun Mass Spectrom 21, 674-682.

Anthony, R.M., Nimmerjahn, F., Ashline, D.J., Reinhold, V.N., Paulson, J.C., and Ravetch, J.V. (2008). Recapitulation of IVIG anti-inflammatory activity with a recombinant IgG Fc. Science 320, 373-376.

Anumula, K.R. (2000). High-sensitivity and high-resolution methods for glycoprotein analysis. Anal Biochem 283, 17-26.

Anumula, K.R. (2006). Advances in fluorescence derivatization methods for high-performance liquid chromatographic analysis of glycoprotein carbohydrates. Anal Biochem 350, 1-23.

Aoki, K., Perlman, M., Lim, J.M., Cantu, R., Wells, L., and Tiemeyer, M. (2007). Dynamic developmental elaboration of $\mathrm{N}$-linked glycan complexity in the Drosophila melanogaster embryo. J Biol Chem 282, 9127-9142.

Ashline, D., Singh, S., Hanneman, A., and Reinhold, V. (2005). Congruent strategies for carbohydrate sequencing. 1. Mining structural details by MS ${ }^{\mathrm{n}}$. Anal Chem 77, 6250-6262.

Ashline, D.J., Lapadula, A.J., Liu, Y.H., Lin, M., Grace, M., Pramanik, B., et al. (2007). Carbohydrate structural isomers analyzed by sequential mass spectrometry. Anal Chem 79, 3830-3842.

Atwood, J.A., III, Cheng, L., Alvarez-Manilla, G., Warren, N.L., York, W.S., and Orlando, R. (2008). Quantitation by isobaric labeling: applications to glycomics. J Proteome Res 7, 367-374.

Baba, T., Hashimoto, Y., Hasegawa, H., Hirabayashi, A., and Waki, I. (2004). Electron capture dissociation in a radio frequency ion trap. Anal Chem 76, 4263-4266.

Balaguer, E., Demelbauer, U., Pelzing, M., Sanz-Nebot, V., Barbosa, J., and Neususs, C. (2006). Glycoform characterization of erythropoietin combining glycan and intact protein analysis by capillary electrophoresis-electrospray-time-of-flight mass spectrometry. Electrophoresis 27, 2638-2650.

Balaguer, E., and Neususs, C. (2006). Glycoprotein characterization combining intact protein and glycan analysis by capillary electrophoresis-electrospray ionization-mass spectrometry. Anal Chem 78, 5384-5393.

Behr, J.R., Matsumoto, Y., White, F.M., and Sasisekharan, R. (2005). Quantification of isomers from a mixture of twelve heparin and heparan sulfate disaccharides using tandem mass spectrometry. Rapid Commun Mass Spectrom 19, 25532562.

Bennett, C.S., Dean, S.M., Payne, R.J., Ficht, S., Brik, A., and Wong, C.H. (2008). Sugar-assisted glycopeptide ligation with complex oligosaccharides: scope and limitations. J Am Chem Soc 130, 11945-11952.

Bernardes, G.J., Castagner, B., and Seeberger, P.H. (2009). Combined approaches to the synthesis and study of glycoproteins. ACS Chem Biol 4, 703-713.

Bindila, L., Steiner, K., Schaffer, C., Messner, P., Mormann, M., and Peter-Katalinic, J. (2007). Sequencing of O-glycopeptides derived from an S-layer glycoprotein of Geobacillus stearothermophilus NRS 2004/3a containing up to 51 monosaccharide residues at a single glycosylation site by fourier transform ion cyclotron resonance infrared multiphoton dissociation mass spectrometry. Anal Chem 79, 3271-3279.

Bishop, J.R., Schuksz, M., and Esko, J.D. (2007). Heparan sulphate proteoglycans fine-tune mammalian physiology. Nature $446,1030-1037$.

Blixt, O., Head, S., Mondala, T., Scanlan, C., Huflejt, M.E., Alvarez, R., et al. (2004). Printed covalent glycan array for ligand profiling of diverse glycan binding proteins. Proc Natl Acad Sci USA 101, 17033-17038.

Blixt, O., Hoffmann, J., Svenson, S., and Norberg, T. (2008). Pathogen specific carbohydrate antigen microarrays: a chip for detection of Salmonella O-antigen specific antibodies. Glycoconj J 25, 27-36.

Bruntz, R., Dabrowski, U., Dabrowski, J., Ebersold, A., PeterKatalinić, J., and Egge, H., (1988). Fucose-containing oligosaccharides from human milk from a donor of blood group 0 Le(a) nonsecretor. Biol Chem Hoppe Seyler 369, 257-273.

Butler, M., Quelhas, D., Critchley, A.J., Carchon, H., Hebestreit, H.F., Hibbert, R.G., et al. (2003). Detailed glycan analysis of serum glycoproteins of patients with congenital disorders of glycosylation indicates the specific defective glycan processing step and provides an insight into pathogenesis. Glycobiology 13, 601-622.

Campa, C., Coslovi, A., Flamigni, A., and Rossi, M. (2006). Overview on advances in capillary electrophoresis-mass spectrometry of carbohydrates: a tabulated review. Electrophoresis 27, 2027-2050.

Catalina, M.I., Koeleman, C.A., Deelder, A.M., and Wuhrer, M. (2007). Electron transfer dissociation of N-glycopeptides: loss of the entire N-glycosylated asparagine side chain. Rapid Commun Mass Spectrom 21, 1053-1061. 
Chai, W., Piskarev, V., and Lawson, A.M. (2001). Negative-Ion electrospray mass spectrometry of neutral underivatized oligosaccharides. Anal Chem 73, 631-657.

Chai, W., Piskarev, V., and Lawson, A.M. (2002). Branching pattern and sequence analysis of underivatized oligosaccharides by combined MS/MS of singly and doubly charged molecular ions in negative-ion electrospray mass spectrometry. J Am Soc Mass Spectrom 13, 670-679.

Chakraborty, A., and Regnier, F.E. (2002). Global internal standard technology for comparative proteomics. J Chromatogr A 949, 173-184.

Chan, T.W., and Tang, K.Y. (2003). Analysis of a bioactive beta$(1 \rightarrow 3)$ polysaccharide (Curdlan) using matrix-assisted laser desorption/ionization time-of-flight mass spectrometry. Rapid Commun Mass Spectrom 17, 887-896.

Che, F.Y., Shao, X.X., Wang, K.Y., and Xia, Q.C. (1999). Characterization of derivatization of sialic acid with 2-aminoacridone and determination of sialic acid content in glycoproteins by capillary electrophoresis and high performance liquid chromatography-ion trap mass spectrometry. Electrophoresis 20, 2930-2937.

Chen, X., and Flynn, G.C. (2007). Analysis of N-glycans from recombinant immunoglobulin $\mathrm{G}$ by on-line reversed-phase high-performance liquid chromatography/mass spectrometry. Anal Biochem 370, 147-161.

Chi, L., Wolff, J.J., Laremore, T.N., Restaino, O.F., Xie, J., Schiraldi, C., et al. (2008). Structural analysis of bikunin glycosaminoglycan. J Am Chem Soc.

Cipollo, J.F., Costello, C.E., and Hirschberg, C.B. (2002). The fine structure of Caenorhabditis elegans N-glycans. J Biol Chem 277, $49143-49157$.

Cipollo, J.F., Awad, A., Costello, C.E., Robbins, P.W., and Hirschberg, C.B. (2004a). Biosynthesis in vitro of Caenorhabditis elegans phosphorylcholine oligosaccharides. Proc Natl Acad Sci USA 101, 3404-3408.

Cipollo, J.F., Awad, A.M., Costello, C.E., and Hirschberg, C.B. (2004b). srf-3, a mutant of Caenorhabditis elegans, resistant to bacterial infection and to biofilm binding, is deficient in glycoconjugates. J Biol Chem 279, 52893-52903.

Ciucanu, I., and Costello, C.E. (2003). Elimination of oxidative degradation during the per-O-methylation of carbohydrates. J Am Chem Soc 125, 16213-16219.

Ciucanu, I., and Kerek, F. (1984). A simple and rapid method for the permethylation of carbohydrates. Carbohydr Res 131, 209217.

Clowers, B.H., and Hill, H.H. (2005). Mass analysis of mobility-selected ion populations using dual gate, ion mobility, quadrupole ion trap mass spectrometry. Anal Chem 77, 5877-5885.

Clowers, B.H., Dwivedi, P., Steiner, W.E., Hill, H.H., Jr., and Bendiak, B. (2005). Separation of sodiated isobaric disaccharides and trisaccharides using electrospray ionizationatmospheric pressure ion mobility-time of flight mass spectrometry. J Am Soc Mass Spectrom 16, 660-669.

Cooke, C.L., An, H.J., Kim, J., Solnick, J.V., and Lebrilla, C.B. (2007). Method for profiling mucin oligosaccharides from gastric biopsies of rhesus monkeys with and without Helicobacter pylori infection. Anal Chem 79, 8090-8097.

Costello, C.E., Contado-Miller, J.M., and Cipollo, J.F. (2007). A glycomics platform for the analysis of permethylated oligosaccharide alditols. J Am Soc Mass Spectrom 18, 1799-1812.

Cummings, R. (1994). Use of lectins in analysis of glycoconjugates. Methods Enzymol 230, 66-86.
Cummings, R.D., and Kornfeld, S. (1982). Fractionation of asparagine-linked oligosaccharides by serial lectin-Agarose affinity chromatography. A rapid, sensitive, and specific technique. J Biol Chem 257, 11235-11240.

Deery, M.J., Stimson, E., and Chappell, C.G. (2001). Size exclusion chromatography/mass spectrometry applied to the analysis of polysaccharides. Rapid Commun Mass Spectrom 15, 2273-2283.

Deguchi, K., Ito, H., Takegawa, Y., Shinji, N., Nakagawa, H., and Nishimura, S. (2006a). Complementary structural information of positive- and negative-ion MSn spectra of glycopeptides with neutral and sialylated N-glycans. Rapid Commun Mass Spectrom 20, 741-746.

Deguchi, K., Takegawa, Y., Ito, H., Miura, N., Yoshioka, S., Nagai, S., et al. (2006b). Structural assignment of isomeric 2-aminopyridine-derivatized monosialylated biantennary $\mathrm{N}$-linked oligosaccharides using negative-ion multistage tandem mass spectral matching. Rapid Commun Mass Spectrom 20, 412-418.

Deguchi, K., Ito, H., Baba, T., Hirabayashi, A., Nakagawa, H., Fumoto, M., et al. (2007). Structural analysis of O-glycopeptides employing negative- and positive-ion multi-stage mass spectra obtained by collision-induced and electron-capture dissociations in linear ion trap time-of-flight mass spectrometry. Rapid Commun Mass Spectrom 21, 691-698.

Desaire, H., and Leary, J. (2000). Detection and quantification of the sulfated disaccharides in chondroitin sulfate by electrospray tandem mass spectrometry. J Am Soc Mass Spectrom 11, 916-920.

Desaire, H., Sirich, T.L., and Leary, J.A. (2001). Evidence of block and randomly sequenced chondroitin polysaccharides: sequential enzymatic digestion and quantification using ion trap tandem mass spectrometry. Anal Chem 73, 3513-3520.

Domon, B., and Costello, C.E. (1988a). Structure elucidation of glycosphingolipids and gangliosides using high-performance tandem mass spectrometry. Biochemistry 27, 1534-1543.

Domon, B., and Costello, C.E. (1988b). A systematic nomenclature for carbohydrate fragmentations in FAB-MS/MS spectra of glycoconjugates. Glycoconj J 5, 397-409.

Dreisewerd, K., Kolbl, S., Peter-Katalinić, J., Berkenkamp, S., and Pohlentz, G. (2006). Analysis of native milk oligosaccharides directly from thin-layer chromatography plates by matrixassisted laser desorption/ionization orthogonal-time-of-flight mass spectrometry with a glycerol matrix. J Am Soc Mass Spectrom 17, 139-150.

Dwek, M.V., and Brooks, S.A. (2004). Harnessing changes in cellular glycosylation in new cancer treatment strategies. Curr Cancer Drug Targets 4, 425-442.

Dwivedi, P., Bendiak, B., Clowers, B.H., and Hill, H.H., Jr. (2007). Rapid resolution of carbohydrate isomers by electrospray ionization ambient pressure ion mobility spectrometry-time-offlight mass spectrometry (ESI-APIMS-TOFMS). J Am Soc Mass Spectrom 18, 1163-1175.

Ernst, S., Langer, R., Cooney, C.L., and Sasisekharan, R. (1995). Enzymatic degradation of glycosaminoglycans. Crit Rev Biochem Mol Biol 30, 387-444.

Esko, J.D., and Selleck, S.B. (2002). Order out of chaos: assembly of ligand binding sites in heparan sulfate. Annu Rev Biochem $71,435-471$.

Estrella, R.P., Whitelock, J.M., Packer, N.H., and Karlsson, N.G. (2007). Graphitized carbon LC-MS characterization of the chondroitin sulfate oligosaccharides of aggrecan. Anal Chem 79, 3597-3606. 
Evangelista, R.A., Liu, M.S., and Chen, F.T.A. (1995). Characterization of 9-aminopyrene-1,4,6-trisulfonate-derivatized sugars by capillary electrophoresis with laser-induced fluorescence detection. Anal Chem 67, 2239-2245.

Feizi, T., and Chai, W. (2004). Oligosaccharide microarrays to decipher the glyco code. Nat Rev Mol Cell Biol 5, 582-588.

Feizi, T., Fazio, F., Chai, W., and Wong, C.-H. (2003). Carbohydrate microarrays-a new set of technologies at the frontiers of glycomics. Curr Opin Struct Biol 13, 637-645.

Furukawa, J., Shinohara, Y., Kuramoto, H., Miura, Y., Shimaoka, H., Kurogochi, M., et al. (2008). Comprehensive approach to structural and functional glycomics based on chemoselective glycoblotting and sequential tag conversion. Anal Chem 80, 1094-1101.

Fuster, M.M., and Esko, J.D. (2005). The sweet and sour of cancer: glycans as novel therapeutic targets. Nat Rev Cancer 5, $526-542$.

Geng, M., Zhang, X., Bina, M., and Regnier, F. (2001). Proteomics of glycoproteins based on affinity selection of glycopeptides from tryptic digests. J Chromatogr B Biomed Sci Appl 752, 293-306.

Gennaro, L.A., and Salas-Solano, O. (2008). On-line CE-LIF-MS technology for the direct characterization of N-linked glycans from therapeutic antibodies. Anal Chem 80, 3838-3845.

Gennaro, L.A., Delaney, J., Vouros, P., Harvey, D.J., and Domon, B. (2002). Capillary electrophoresis/electrospray ion trap mass spectrometry for the analysis of negatively charged derivatized and underivatized glycans. Rapid Commun Mass Spectrom 16, 192-200.

Gennaro, L.A., Harvey, D.J., and Vouros, P. (2003). Reversedphase ion-pairing liquid chromatography/ion trap mass spectrometry for the analysis of negatively charged, derivatized glycans. Rapid Commun Mass Spectrom 17, 1528-1534.

Gennaro, L.A., Salas-Solano, O., and Ma, S. (2006). Capillary electrophoresis-mass spectrometry as a characterization tool for therapeutic proteins. Anal Biochem 355, 249.

Goldberg, D., Bern, M., Parry, S., Sutton-Smith, M., Panico, M., Morris, H.R., et al. (2007). Automated N-glycopeptide identification using a combination of single- and tandem-MS. J Proteome Res 6, 3995-4005.

Guile, G.R., Rudd, P.M., Wing, D.R., Prime, S.B., and Dwek, R.A. (1996). A rapid high-resolution high-performance liquid chromatographic method for separating glycan mixtures and analyzing oligosaccharide profiles. Anal Biochem 240, 210-226.

Hacker, U., Nybakken, K., and Perrimon, N. (2005). Heparan sulphate proteoglycans: the sweet side of development. Nat Rev Mol Cell Biol 6, 530-541.

Håkansson, K., Cooper, H.J., Emmett, M.R., Costello, C.E., Marshall, A.G., and Nilsson, C.L. (2001). Electron capture dissociation and Infrared multiphoton dissociation MS/MS of an $\mathrm{N}$-glycosylated tryptic peptide to yield complementary sequence information. Anal Chem 73, 4530-4536.

Hakansson, K., Chalmers, M.J., Quinn, J.P., McFarland, M.A., Hendrickson, C.L., and Marshall, A.G. (2003). Combined electron capture and infrared multiphoton dissociation for multistage MS/MS in a Fourier transform ion cyclotron resonance mass spectrometer. Anal Chem 75, 3256-3262.

Haltiwanger, R.S., and Lowe, J.B. (2004). Role of glycosylation in development. Annu Rev Biochem 73, 491-537.

Hanneman, A.J., Rosa, J.C., Ashline, D., and Reinhold, V.N. (2006). Isomer and glycomer complexities of core GlcNAcs in Caenorhabditis elegans. Glycobiology 16, 874-890.
Hart, G.W., Housley, M.P., and Slawson, C. (2007). Cycling of O-linked beta-N-acetylglucosamine on nucleocytoplasmic proteins. Nature 446, 1017-1022.

Harvey, D.J. (1999). Matrix-assisted laser desorption/ionization mass spectrometry of carbohydrates. Mass Spectrom Rev 18, 349-450.

Harvey, D.J. (2000a). Collision-induced fragmentation of underivatized $N$-linked carbohydrates ionized by electrospray. J Mass Spectrom 35, 1178-1190.

Harvey, D.J. (2000b). Electrospray mass spectrometry and fragmentation of $N$-linked carbohydrates derivatized at the reducing terminus. J Am Soc Mass Spectrom 11, 900-915.

Harvey, D.J. (2003). Matrix-assisted laser desorption/ionization mass spectrometry of carbohydrates and glycoconjugates. Int J Mass Spectrom 226, 1-35.

Harvey, D.J. (2005a). Fragmentation of negative ions from carbohydrates: part 1 . Use of nitrate and other anionic adducts for the production of negative ion electrospray spectra from $\mathrm{N}$-linked carbohydrates. J Am Soc Mass Spectrom 16, 622-630.

Harvey, D.J. (2005b). Fragmentation of negative ions from carbohydrates: part 2. fragmentation of high-mannose $\mathrm{N}$-linked glycans. J Am Soc Mass Spectrom 16, 631-646.

Harvey, D.J. (2005c). Fragmentation of negative ions from carbohydrates: part 3. fragmentation of hybrid and complex N-linked glycans. J Am Soc Mass Spectrom 16, 647-659.

Harvey, D.J. (2006). Analysis of carbohydrates and glycoconjugates by matrix-assisted laser desorption/ionization mass spectrometry: an update covering the period 1999-2000. Mass Spectrom Rev 25, 595-662.

Harvey, D.J. (2008). Analysis of carbohydrates and glycoconjugates by matrix-assisted laser desorption/ionization mass spectrometry: an update covering the period 2001-2002. Mass Spectrom Rev 27, 125-201.

Harvey, D.J., Royle, L., Radcliffe, C.M., Rudd, P.M., and Dwek, R.A. (2008). Structural and quantitative analysis of N-linked glycans by matrix-assisted laser desorption ionization and negative ion nanospray mass spectrometry. Anal Biochem $376,40-60$.

Hato, M., Nakagawa, H., Kurogochi, M., Akama, T.O., Marth, J.D., Fukuda, M.N., et al. (2006). Unusual N-glycan structures in alpha-mannosidase II/IIx double null embryos identified by a systematic glycomics approach based on two-dimensional LC mapping and matrix-dependent selective fragmentation method in MALDI-TOF/TOF mass spectrometry. Mol Cell Proteomics 5, 2146-2157.

Henriksen, J., Ringborg, L.H., and Roepstorrf, P. (2004). On-line size-exclusion chromatography/mass spectrometry of low molecular mass heparin. J Mass Spectrom 39, 1305-1312.

Hirabayashi, J. (2008). Concept, strategy and realization of lectin-based glycan profiling. J Biochem 144, 139-147.

Hirabayashi, J., and Kasai, K. (2002). Separation technologies for glycomics. J Chromatogr B Anal Technol Biomed Life Sci 771, 67-87.

Hitchcock, A., Yates, K.E., Costello, C., and Zaia, J. (2008). Comparative glycomics of connective tissue glycosaminoglycans. Proteomics 8, 1384-1397.

Hitchcock, A.M., Costello, C.E., and Zaia, J. (2006a). Glycoform quantification of chondroitin/dermatan sulfate using an LC/ MS/MS platform. Biochemistry 45, 2350-2361.

Hitchcock, A.M., Yates, K.E., Shortkroff, S., Costello, C.E., and Zaia, J. (2006b). Optimized extraction of glycosaminoglycans from normal and osteoarthritic cartilage for glycomics profiling. Glycobiology 17, 25-35. 
Hogan, J.M., Pitteri, S.J., Chrisman, P.A., and McLuckey, S.A. (2005). Complementary structural information from a tryptic $\mathrm{N}$-linked glycopeptide via electron transfer ion/ion reactions and collision-induced dissociation. J Proteome Res 4, 628-632.

Hsieh-Wilson, L.C. (2007). Bioorganic chemistry: a sweet synthesis. Nature 445, 31-33.

Hulsmeier, A.J., Paesold-Burda, P., and Hennet, T. (2007). $\mathrm{N}$-glycosylation site occupancy in serum glycoproteins using multiple reaction monitoring liquid chromatography-mass spectrometry. Mol Cell Proteomics 6, 2132-2138.

Isailovic, D., Kurulugama, R.T., Plasencia, M.D., Stokes, S.T., Kyselova, Z., Goldman, R., et al. (2008). Profiling of human serum glycans associated with liver cancer and cirrhosis by IMS-MS. J Proteome Res 7, 1109-1117.

Ito, H., Yamada, K., Deguchi, K., Nakagawa, H., and Nishimura, S. (2007). Structural assignment of disialylated biantennary $\mathrm{N}$-glycan isomers derivatized with 2-aminopyridine using negative-ion multistage tandem mass spectral matching. Rapid Commun Mass Spectrom 21, 212-218.

Itoh, S., Kawasaki, N., Ohta, M., and Hayakawa, T. (2002). Structural analysis of a glycoprotein by liquid chromatographymass spectrometry and liquid chromatography with tandem mass spectrometry-application to recombinant human thrombomodulin. J Chromatogr 978, 141-152.

Kaji, H., Saito, H., Yamauchi, Y., Shinkawa, T., Taoka, M., Hirabayashi, J., et al. (2003). Lectin affinity capture, isotope-coded tagging and mass spectrometry to identify N-linked glycoproteins. Nat Biotechnol 21, 667-672.

Kaji, H., Yamauchi, Y., Takahashi, N., and Isobe, T. (2007). Mass spectrometric identification of $\mathrm{N}$-linked glycopeptides using lectin-mediated affinity capture and glycosylation site-specific stable isotope tagging. Nat Protocols 1, 3019-3027.

Kang, P., Mechref, Y., Klouckova, I., and Novotny, M.V. (2005). Solid-phase permethylation of glycans for mass spectrometric analysis. Rapid Commun Mass Spectrom 19, 3421-3428.

Kang, P., Mechref, Y., Kyselova, Z., Goetz, J.A., and Novotny, M.V. (2007). Comparative glycomic mapping through quantitative permethylation and stable-isotope labeling. Anal Chem 79, 6064-6073.

Karas, M., and Hillenkamp, F. (1988). Laser desorption ionization of proteins with molecular masses exceeding 10,000 daltons. Anal Chem 60, 2299-2301.

Karas, M., Bachmann, D., Bahr, U., and Hillenkamp, F. (1987). Matrix-assisted ultraviolet-laser desorption of nonvolatile compounds. Int J Mass Spectrom Ion Process 78, 53-68.

Karas, M., Bahr, U., and Dulcks, T. (2000). Nano-electrospray ionization mass spectrometry: addressing analytical problems beyond routine. Fresenius J Anal Chem 366, 669-676.

Karlsson, N.G., Wilson, N.L., Wirth, H.J., Dawes, P., Joshi, H., and Packer, N.H., 2004. Negative ion graphitised carbon nano-liquid chromatography/mass spectrometry increases sensitivity for glycoprotein oligosaccharide analysis. Rapid Commun Mass Spectrom 18, 2282-2292.

Kawasaki, N., Itoh, S., Ohta, M., and Hayakawa, T. (2003). Microanalysis of $\mathrm{N}$-linked oligosaccharides in a glycoprotein by capillary liquid chromatography/mass spectrometry and liquid chromatography/tandem mass spectrometry. Anal Biochem 316, 15-22.

Kirmiz, C., Li, B., An, H.J., Clowers, B.H., Chew, H.K., Lam, K.S., et al. (2007). A serum glycomics approach to breast cancer biomarkers. Mol Cell Proteomics 6, 43-55.

Kjeldsen, F., Haselmann, K.F., Budnik, B.A., Sorensen, E.S., and Zubarev, R.A., 2003. Complete characterization of posttrans- lational modification sites in the bovine milk protein PP3 by tandem mass spectrometry with electron capture dissociation as the last stage. Anal Chem 75, 2355-2361.

Klockow, A., Amado, R., Widmer, H.M., Paulus, A., 1995. Separation of 8-aminonaphthalene-1,3,6-trisulfonic acid-labelled neutral and sialylated $\mathrm{N}$-linked complex oligosaccharides by capillary electrophoresis. J Chromatogr A 716, 241-247.

Knezevic, A., Polasek, O., Gornik, O., Rudan, I., Campbell, H., Hayward, C., et al. (2009). Variability, heritability and environmental determinants of human plasma N-glycome. J Proteome Res 8, 694-701.

Kreuger, J., Spillmann, D., Li, J.P., and Lindahl, U. (2006). Interactions between heparan sulfate and proteins: the concept of specificity. J Cell Biol 174, 323-327.

Kuberan, B., Lech, M., Zhang, L., Wu, Z.L., Beeler, D.L., and Rosenberg, R. (2002). Analysis of heparan sulfate oligosaccharides with ion pair-reverse phase capillary high performance liquid chromatography-microelectrospray ionization time-of-flight mass spectrometry. J Am Chem Soc 124, 87078718.

Kunz, C., Rudloff, S., Baier, W., Klein, N., and Strobel, S. (2000). Oligosaccharides in human milk: structural, functional, and metabolic aspects. Annu Rev Nutr 20, 699-722.

Kuraya, N., and Hase, S. (1996). Analysis of pyridylaminated O-linked sugar chains by two-dimensional sugar mapping. Anal Biochem 233, 205-211.

Lapadula, A.J., Hatcher, P.J., Hanneman, A., Ashline, D.J., Zhang, H., and Reinhold, V.N. (2005). Congruent strategies for carbohydrate sequencing. 3. OSCAR: an algorithm for assigning oligosaccharide topology from $\mathrm{MS}^{\mathrm{n}}$ data. Anal Chem $77,6271-6279$

Larsen, M.R., Hojrup, P., and Roepstorff, P. (2005). Characterization of gel-separated glycoproteins using two-step proteolytic digestion combined with sequential microcolumns and mass spectrometry. Mol Cell Proteomics 4, 107-119.

Lauc, G. (2006). Sweet secret of the multicellular life. Biochim Biophys Acta 1760, 525-526.

Lawrence, R., Olson, S.K., Steele, R.E., Wang, L., Warrior, R., Cummings, R.D., et al. (2008). Evolutionary differences in glycosaminoglycan fine structure detected by quantitative glycan reductive isotope labeling. J Biol Chem 283, 3367433684.

Leavell, M.D., and Leary, J.A. (2001). Stabilization and linkage analysis of metal-ligated sialic acid containing oligosaccharides. J Am Soc Mass Spectrom 12, 528-536.

Lemoine, J., Strecker, G., Leroy, Y., Fournet, B., and Ricart, G. (1991). Collisional-activation tandem mass spectrometry of sodium adduct ions of methylated oligosaccharides: sequence analysis and discrimination between alpha-NeuAc-(2-3) and alpha-NeuAc-(2-6) linkages. Carbohydr Res 221, 209-217.

Lemoine, J., Fournet, B., Despeyroux, D., Jennings, K.R., Rosenberg, R., DeHoffmann, E. (1993). Collision-induced dissociation of alkali-metal cationized and permethylated oligosaccharides-influence of the collision energy and of the collision gas for the assignment of linkage position. J Am Soc Mass Spectrom 4, 197-203.

Liang, P.H., Wu, C.Y., Greenberg, W.A., Wong, C.H. (2008). Glycan arrays: biological and medical applications. Curr Opin Chem Biol 12, 86-92.

Locascio, R.G., Ninonuevo, M.R., Freeman, S.L., Sela, D.A., Grimm, R., Lebrilla, C.B., et al. (2007). Glycoprofiling of bifidobacterial consumption of human milk oligosaccharides demonstrates strain specific, preferential consumption of 
small chain glycans secreted in early human lactation. J Agric Food Chem 55, 8914-8919.

Madera, M., Mechref, Y., and Novotny, M.V. (2005). Combining lectin microcolumns with high-resolution separation techniques for enrichment of glycoproteins and glycopeptides. Anal Chem 77, 4081-4090.

Madera, M., Mechref, Y., Klouckova, I., and Novotny, M.V. (2006). Semiautomated high-sensitivity profiling of human blood serum glycoproteins through lectin preconcentration and multidimensional chromatography/tandem mass spectrometry. J Proteome Res 5, 2348-2363.

Mason, K.E., Meikle, P.J., Hopwood, J.J., and Fuller, M. (2006). Characterization of sulfated oligosaccharides in mucopolysaccharidosis type IIIA by electrospray ionization mass spectrometry. Anal Chem 78, 4534-4542.

Matsuno, Y.-K., Yamada, K., Tanabe, A., Kinoshita, M., Maruyama, S.-Z., Osaka, Y.-S., et al. (2007). Development of an apparatus for rapid release of oligosaccharides at the glycosaminoglycan-protein linkage region in chondroitin sulfatetype proteoglycans. Anal Biochem 362, 245-257.

Mattu, T.S., Royle, L., Langridge, J., Wormald, M.R., Van den Steen, P.E., Van Damme, J., et al. (2000). O-glycan analysis of natural human neutrophil gelatinase $\mathrm{B}$ using a combination of normal phase-HPLC and online tandem mass spectrometry: implications for the domain organization of the enzyme. Biochemistry 39, 15695-15704.

McClellan, J.M., Costello, C.E., O'Connor, P.B., and Zaia, J. (2002). Influence of charge state on product ion mass spectra and the determination of $4 \mathrm{~S} / 6 \mathrm{~S}$ sulfation sequence of chondroitin sulfate oligosaccharides. Anal Chem 74, 3760-3771.

Mechref, Y., and Novotny, M.V. (2006). Miniaturized separation techniques in glycomic investigations. J Chromatogr B Anal Technol Biomed Life Sci.

Mechref, Y., and Novotny, M.V. (2009). Glycomic analysis by capillary electrophoresis-mass spectrometry. Mass Spectrom Rev 28, 207-222.

Mechref, Y., Kang, P., and Novotny, M.V. (2006). Differentiating structural isomers of sialylated glycans by matrix-assisted laser desorption/ionization time-of-flight/time-of-flight tandem mass spectrometry. Rapid Commun Mass Spectrom 20, 1381-1389.

Meng, C.K., Mann, M., and Fenn, J.B. (1988). Of protons or proteins. Z Phys D 10, 361-368.

Militsopoulou, M., Lamari, F.N., Hjerpe, A., and Karamanos, N.K. (2002). Determination of twelve heparin- and heparan sulfate-derived disaccharides as 2-aminoacridone derivatives by capillary zone electrophoresis using ultraviolet and laserinduced fluorescence detection. Electrophoresis 23, 1104-1109.

Miller, M.J.C., Costello, C.E., Malmström, A., and Zaia, J. (2006). A tandem mass spectrometric approach to determination of chondroitin/dermatan sulfate oligosaccharide glycoforms. Glycobiology 16, 502-513.

Moyer, S.C., and Cotter, R.J. (2002). Atmospheric pressure MALDI. Anal Chem 74, 468A-476A.

Moyer, S.C., Marzilli, L.A., Woods, A., Laiko, V.V., Doroshenko, V.M., and Cotter, R.J. (2002). Atmospheric pressure matrixassisted laser desorption/ionization (AP MALDI) on a quadrupole ion trap mass spectrometer. Int J Mass Spectrom 226, 133-150.

Naimy, H., Leymarie, N., Bowman, M., and Zaia, J. (2008). Characterization of heparin oligosaccharides binding specifically to antithrombin III using mass spectrometry. Biochemistry $47,3155-3161$.
Nakano, M., Higo, D., Arai, E., Nakagawa, T., Kakehi, K., Taniguchi, N., et al. (2009). Capillary electrophoresis-electrospray ionization mass spectrometry for rapid and sensitive N-glycan analysis of glycoproteins as 9-fluorenylmethyl derivatives. Glycobiology 19, 135-143.

Niñonuevo, M., An, H., Yin, H., Killeen, K., Grimm, R., Ward, R., et al. (2005). Nanoliquid chromatography-mass spectrometry of oligosaccharides employing graphitized carbon chromatography on microchip with a high-accuracy mass analyzer. Electrophoresis 26, 3641-3649.

Ninonuevo, M.R., Park, Y., Yin, H., Zhang, J., Ward, R.E., Clowers, B.H., et al. (2006). A strategy for annotating the human milk glycome. J Agric Food Chem 54, 7471-7480.

Ninonuevo, M.R., Perkins, P.D., Francis, J., Lamotte, L.M., Locascio, R.G., Freeman, S.L., et al. (2008). Daily variations in oligosaccharides of human milk determined by microfluidic chips and mass spectrometry. J Agric Food Chem 56, 618-626.

O'Connor, P.B., and Costello, C.E. (2001). A high pressure matrix-assisted laser desorption/ionization Fourier transform mass spectrometry ion source for thermal stabilization of labile biomolecules. Rapid Commun Mass Spectrom 15, 18621868.

O'Connor, P.B., Mirgorodskaya, E., and Costello, C.E. (2002). High pressure matrix-assisted laser desorption/ionization Fourier transform mass spectrometry for minimization of ganglioside fragmentation. J Am Soc Mass Spectrom 13, 402407.

Pabst, M., Bondili, J.S., Stadlmann, J., Mach, L., and Altmann, F. (2007). Mass +retention time $=$ structure: a strategy for the analysis of N-glycans by carbon LC-ESI-MS and its application to fibrin N-glycans. Anal Chem 79, 5051-5057.

Patwa, T.H., Zhao, J., Anderson, M.A., Simeone, D.M., and Lubman, D.M. (2006). Screening of glycosylation patterns in serum using natural glycoprotein microarrays and multi-lectin fluorescence detection. Anal Chem 78, 6411-6421.

Pfenninger, A., Karas, M., Finke, B., and Stahl, B. (2002a). Structural analysis of underivatized neutral human milk oligosaccharides in the negative ion mode by nano-electrospray $\mathrm{MS}^{\mathrm{n}}$ (part 1: methodology). J Am Soc Mass Spectrom 13, 13311340.

Pfenninger, A., Karas, M., Finke, B., and Stahl, B. (2002b). Structural analysis of underivatized neutral human milk oligosaccharides in the negative ion mode by nano-electrospray $\mathrm{MS}^{\mathrm{n}}$ (part 2: application to isomeric mixtures). J Am Soc Mass Spectrom 13, 1341-1348.

Plavina, T., Wakshull, E., Hancock, W.S., and Hincapie, M. (2007). Combination of abundant protein depletion and multilectin affinity chromatography (M-LAC) for plasma protein biomarker discovery. J Proteome Res 6, 662-671.

Prien, J.M., Huysentruyt, L.C., Ashline, D.J., Lapadula, A.J., Seyfried, T.N., and Reinhold, V.N. (2008). Differentiating $\mathrm{N}$-linked glycan structural isomers in metastatic and nonmetastatic tumor cells using sequential mass spectrometry. Glycobiology 18, 353-366.

Prior, J.L., Prior, R.G., Hitchen, P.G., Diaper, H., Griffin, K.F., Morris, H.R., et al. (2003). Characterization of the $\mathrm{O}$ antigen gene cluster and structural analysis of the $\mathrm{O}$ antigen of Francisella tularensis subsp. tularensis. J Med Microbiol 52, 845851.

Qiu, R., and Regnier, F.E. (2005). Comparative glycoproteomics of N-linked complex-type glycoforms containing sialic acid in human serum. Anal Chem 77, 7225-7231. 
Renfrow, M.B., Cooper, H.J., Tomana, M., Kulhavy, R., Hiki, Y., Toma, K., et al. (2005). Determination of aberrant $\mathrm{O}$-glycosylation in the IgA1 hinge region by electron capture dissociation fourier transform-ion cyclotron resonance mass spectrometry. J Biol Chem 280, 19136-19145.

Renfrow, M.B., Mackay, C.L., Chalmers, M.J., Julian, B.A., Mestecky, J., Kilian, M., et al. (2007). Analysis of O-glycan heterogeneity in IgA1 myeloma proteins by Fourier transform ion cyclotron resonance mass spectrometry: implications for IgA nephropathy. Anal Bioanal Chem 389, 1397-1407.

Ressom, H.W., Varghese, R.S., Goldman, L., An, Y., Loffredo, C.A., Abdel-Hamid, M., et al. (2008). Analysis of MALDI-TOF mass spectrometry data for discovery of peptide and glycan biomarkers of hepatocellular carcinoma. J Proteome Res 7, 603-610.

Royle, L., Mattu, T.S., Hart, E., Langridge, J.I., Merry, A.H., Murphy, N., et al. (2002). An analytical and structural database provides a strategy for sequencing $\mathrm{O}$-glycans from microgram quantities of glycoproteins. Anal Biochem 304, 70-90.

Saad, O.M., and Leary, J.A. (2003). Compositional analysis and quantification of heparin and heparan sulfate by electrospray ionization ion trap mass spectrometry. Anal Chem 75, 29852995.

Saad, O.M., Ebel, H., Uchimura, K., Rosen, S.D., Bertozzi, C.R., and Leary, J.A. (2005). Compositional profiling of heparin/ heparan sulfate using mass spectrometry: assay for specificity of a novel extracellular human endosulfatase. Glycobiology $15,818-826$.

Saba, J.A., Shen, X.D., Jamieson, J.C., and Perreault, H. (2001). Investigation of different combinations of derivatization, separation methods and electrospray ionization mass spectrometry for standard oligosaccharides and glycans from ovalbumin. J Mass Spectrom 36, 563-574.

Sagi, D., Peter-Katalinić, J., Conradt, H.S., and Nimtz, M. (2002). Sequencing of tri- and tetraantennary $\mathrm{N}$-glycans containing sialic acid by negative mode ESI QTOF tandem MS. J Am Soc Mass Spectrom 13, 1138-1148.

Sakai, S., Hirano, K., Toyoda, H., Linhardt, R.J., and Toida, T. (2007). Matrix assisted laser desorption ionization-time of flight mass spectrometry analysis of hyaluronan oligosaccharides. Anal Chim Acta 593, 207-213.

Satterfield, M.B., and Welch, M.J. (2005). Comparison by LC-MS and MALDI-MS of prostate-specific antigen from five commercial sources with certified reference material 613. Clin Biochem 38, 166-174.

Schenauer, M.R., Meissen, J.K., Seo, Y., Ames, J.B., and Leary, J.A. (2009). Heparan sulfate separation, sequencing, and isomeric differentiation: ion mobility spectrometry reveals specific iduronic and glucuronic acid-containing hexasaccharides. Anal Chem 81, 10179-10185.

Schulz, B.L., Sloane, A.J., Robinson, L.J., Prasad, S.S., Lindner, R.A., Robinson, M., et al. (2007). Glycosylation of sputum mucins is altered in cystic fibrosis patients. Glycobiology 17, 698-712.

Seeberger, P.H., and Werz, D.B. (2007). Synthesis and medical applications of oligosaccharides. Nature 446, 1046-1051.

Seipert, R.R., Dodds, E.D., Clowers, B.H., Beecroft, S.M., German, J.B., and Lebrilla, C.B. (2008). Factors that influence fragmentation behavior of N-linked glycopeptide ions. Anal Chem 80, 3684-3692.

Sheeley, D.M., and Reinhold, V.N. (1998). Structural characterization of carbohydrate sequence, linkage, and branching in a quadrupole Ion trap mass spectrometer: neutral oligosaccharides and $N$-linked glycans. Anal Chem 70, 3053-3059.
Sparbier, K., Koch, S., Kessler, I., Wenzel, T., and Kostrzewa, M. (2005). Selective isolation of glycoproteins and glycopeptides for MALDI-TOF MS detection supported by magnetic particles. J Biomol Tech 16, 407-413.

Stahl, B., Thurl, S., Zeng, J., Karas, M., Hillenkamp, F., Steup, M., et al. (1994). Oligosaccharides from human milk as revealed by matrix-assisted laser desorption/ionization mass spectromctrometry. Anal Biochem 223, 218-226.

Staples, G., Bowman, M., Costello, C.E., Hitchcock, A., Lau, J., Leymarie, N., et al. (2009). A chip-based amide-HILIC LC/MS platform for glycosaminoglycan lycomics. Proteomics 9, 686695.

Staples, G., Naimy, H., Yin, H., Kileen, K., Kraiczek, K., Costello, C.E., et al. (2010). Improved hydrophilic interaction chromatography LC/MS of heparinoids using a chip with postcolumn make-up flow. Anal Chem [Epub ahead of print].

Steiner, K., Pohlentz, G., Dreisewerd, K., Berkenkamp, S., Messner, P., Peter-Katalinic, J., et al. (2006). New insights into the glycosylation of the surface layer protein SgsE from Geobacillus stearothermophilus NRS 2004/3a. J Bacteriol 188, 7914-7921.

Suzuki, H., Muller, O., Guttman, A., and Karger, B.L. (1997). Analysis of 1-aminopyrene-3,6,8-trisulfonate-derivatized oligosaccharides by capillary electrophoresis with matrix-assisted laser desorption/ionization time-of-flight mass spectrometry. Anal Chem 69, 4554-4559.

Suzuki, Y., Suzuki, M., Ito, E., Ishii, H., Miseki, K., and Suzuki, A. (2005). Convenient and rapid analysis of linkage isomers of fucose-containing oligosaccharides by matrix-assisted laser desorption/ionization quadrupole ion trap time-of-flight mass spectrometry. Glycoconj J 22, 427-431.

Thakur, D., Rejtar, T., Karger, B.L., Washburn, N.J., Bosques, C.J., Gunay, N.S., et al. (2009). Profiling the glycoforms of the intact alpha subunit of recombinant human chorionic gonadotropin by high-resolution capillary electrophoresis-mass spectrometry. Anal Chem 81, 8900-8907.

Thanawiroon, C., Rice, K.G., Toida, T., and Linhardt, R.J. (2004). LC/MS sequencing approach for highly sulfated heparinderived oligosaccharides. J Biol Chem 279, 2608-2615.

Tian, Y., Zhou, Y., Elliott, S., Aebersold, R., and Zhang, H. (2007). Solid-phase extraction of N-linked glycopeptides. Nat Protocols 2, 334-339.

Tseng, K., Lindsay, L.L., Penn, S., Hedrick, J.L., and Lebrilla, C.B. (1997). Characterization of neutral oligosaccharide-alditols from Xenopus laevis egg jelly coats by matrix-assisted laser desorption Fourier transform mass spectrometry. Anal Biochem 250, 18-28.

Tseng, K., Hedrick, J.L., and Lebrilla, C.B. (1999). Catalog-library approach for the rapid and sensitive structural elucidation of oligosaccharides. Anal Chem 71, 3747-3754.

Tseng, K., Xie, Y., Seeley, J., Hedrick, J.L., and Lebrilla, C.B. (2001). Profiling with structural elucidation of the neutral and anionic $O$-linked oligosaccharides in the egg jelly coat of Xenopus laevis by Fourier transform mass spectrometry. Glycoconj J 18, 309-320.

Vakhrushev, S.Y., Zamfir, A., and Peter-Katalinić, J. (2004). ${ }^{0,2} \mathrm{~A}_{\mathrm{n}}$ cross-ring cleavage as a general diagnostic tool for glycan assignment in glycoconjugate mixtures. J Am Soc Mass Spectrom 15, 1863-1868.

Varki, A. (2006). Nothing in glycobiology makes sense, except in the light of evolution. Cell 126, 841-845.

Viseux, N., Costello, C.E., and Domon, B. (1999). Post-source decay mass spectrometry: optimized calibration procedure and structural characterization of permethylated oligosaccharides. J Mass Spectrom 34, 364-376. 
Viseux, N., de Hoffmann, E., and Domon, B. (1997). Structural analysis of permethylated oligosaccharides by electrospray tandem mass spectrometry. Anal Chem 69, 3193-3198.

Wada, Y., Tajiri, M., and Yoshida, S. (2004). Hydrophilic affinity isolation and MALDI multiple-stage tandem mass spectrometry of glycopeptides for glycoproteomics. Anal Chem 76, 6560-6565.

Wada, Y., Azadi, P., Costello, C.E., Dell, A., Dwek, R.A., Geyer, H., et al. (2007). Comparison of the methods for profiling glycoprotein glycans: HUPO HGPI (Human Proteome Organisation Human Disease Glycomics/Proteome Initiative) multi-institutional study. Glycobiology 17, 411-422.

Wang, Y.H., Wu, S.L., and Hancock, W.S. (2006). Approaches to the study of N-linked glycoproteins in human plasma using lectin affinity chromatography and nano-HPLC coupled to electrospray linear ion trap-Fourier transform mass spectrometry. Glycobiology 16, 514-523.

Wheeler, S.F., and Harvey, D.J. (2000). Negative ion mass spectrometry of sialylated carbohydrates: discrimination of $\mathrm{N}$-acetylneuraminic acid linkages by MALDI-TOF and ESITOF mass spectrometry. Anal Chem 72, 5027-5039.

Whitehouse, C.M., Dreyer, R.N., Yamashita, M., and Fenn, J.B. (1985). Electrospray interface for liquid chromatographs and mass spectrometers. Anal Chem 57, 675-679.

Wolff, J.J., Amster, I.J., Chi, L., and Linhardt, R.J. (2007a). Electron detachment dissociation of glycosaminoglycan tetrasaccharides. J Am Soc Mass Spectrom 18, 234-244.

Wolff, J.J., Chi, L., Linhardt, R.J., and Amster, I.J. (2007b). Distinguishing glucuronic from iduronic acid in glycosaminoglycan tetrasaccharides by using electron detachment dissociation. Anal Chem 79, 2015-2022.

Wu, S.L., Huhmer, A.F., Hao, Z., and Karger, B.L. (2007). On-line LC-MS approach combining collision-induced dissociation (CID), electron-transfer dissociation (ETD), and CID of an isolated charge-reduced species for the trace-level characterization of proteins with post-translational modifications. J Proteome Res 6, 4230-4244.

Wuhrer, M., Koeleman, C.A.M., Deelder, A.M., and Hokke, C.N. (2004). Normal-phase nanoscale liquid chromatographymass spectrometry of underivatized oligosaccharides at lowfemtomole sensitivity. Anal Chem 76, 833-838.

Wuhrer, M., Deelder, A.M., and Hokke, C.H. (2005a). Protein glycosylation analysis by liquid chromatography-mass spectrometry. J Chromatogr B Anal Technol Biomed Life Sci 825, 124-133.

Wuhrer, M., Koeleman, C.A., Hokke, C.H., and Deelder, A.M. (2005b). Protein glycosylation analyzed by normal-phase nanoliquid chromatography-mass spectrometry of glycopeptides. Anal Chem 77, 886-894.

Wuhrer, M., Catalina, M.I., Deelder, A.M., and Hokke, C.H. (2007a). Glycoproteomics based on tandem mass spectrometry of glycopeptides. J Chromatogr B Anal Technol Biomed Life Sci 849, 115-128.

Wuhrer, M., Stam, J.C., Van de Geijn, F.E., Koeleman, C.A., Verrips, C.T., Dolhain, R.J., et al. (2007b). Glycosylation profiling of immunoglobulin G (IgG) subclasses from human serum. Proteomics 7, 4070-4081.

Xin, L., Li, M., and Jianjun, L. (2008). Recent developments in the enrichment of glycopeptides for glycoproteomics. Anal Lett 41, 268-277.

Xiong, L., Andrews, D., and Regnier, F. (2003). Comparative proteomics of glycoproteins based on lectin selection and isotope coding. J Proteome Res 2, 618-625.

Yamada, K., Hyodo, S., Matsuno, Y.K., Kinoshita, M., Maruyama, S.Z., Osaka, Y.S., et al. (2007). Rapid and sensitive analysis of mucin-type glycans using an in-line flow glycanreleasing apparatus. Anal Biochem 371, 52-61.

Yamamoto, S., Hase, S., Fukuda, S., Sano, O., and Ikenaka, T. (1989). Structures of the sugar chains of interferon-gamma produced by human myelomonocyte cell line HBL-38. J Biochem (Tokyo) 105, 547-555.

Yang, Z., Hancock, W.S., Chew, T.R., and Bonilla, L. (2005). A study of glycoproteins in human serum and plasma reference standards (HUPO) using multilectin affinity chromatography coupled with RPLC-MS/MS. Proteomics 5, 3353-3366.

Yuan, J., Hashii, N., Kawasaki, N., Itoh, S., Kawanishi, T., and Hayakawa, T. (2005). Isotope tag method for quantitative analysis of carbohydrates by liquid chromatography-mass spectrometry. J Chromatogr 1067, 145.

Zaia, J. (2004). Mass spectrometry of oligosaccharides. Mass Spectrom Rev 23, 161-227.

Zaia, J. (2005). Principles of mass spectrometry of glycosaminoglycans. J Biomacromol Mass Spectrom 1, 3-36.

Zaia, J. (2006). Mass spectrometric ionization of carbohydrates. In Ionization Methods. M.L. Gross, and R. M. Caprioli, R.M., eds. (Elsevier, Amsterdam), pp. 889-903.

Zaia, J. (2007). Mass spectrometric ionization of carbohydrates. In Encyclopedia of Mass Spectrometry, vol. 6. M.G. Gross, and R.M. Caprioli, eds. (Elsevier, New York).

Zaia, J. (2009). On-line separations combined with MS for analysis of glycosaminoglycans. Mass Spectrom Rev 28, 254-272.

Zaia, J., McClellan, J.E., and Costello, C.E. (2001). Tandem mass spectrometric determination of the $4 \mathrm{~S} / 6 \mathrm{~S}$ sulfation sequence in chondroitin sulfate oligosaccharides. Anal Chem 73, 60306039.

Zaia, J., Li, X.-Q., Chan, S.-Y., and Costello, C.E. (2003). Tandem mass spectrometric strategies for determination of sulfation positions and uronic acid epimerization in chondroitin sulfate oligosaccharides. J Am Soc Mass Spectrom 14, 1270-1281.

Zamfir, A., Seidler, D.G., Kresse, H., and Peter-Katalinc, J. (2002). Structural characterization of chondroitin/dermatan sulfate oligosaccharides from bovine aorta by capillary electrophoresis and electrospray ionization quadrupole time-of-flight tandem mass spectrometry. Rapid Commun Mass Spectrom 16, 2015-2024.

Zamfir, A., Seidler, D.G., Schonherr, E., Kresse, H., and PeterKatalinić, J. (2004). On-line sheathless capillary electrophoresis/nanoelectrospray ionization-tandem mass spectrometry for the analysis of glycosaminoglycan oligosaccharides. Electrophoresis 25, 2010-2016.

Zamfir, A.D., Bindila, L., Lion, N., Allen, M., Girault, H.H., and Peter-Katalinić, J. (2005). Chip electrospray mass spectrometry for carbohydrate analysis. Electrophoresis 26, 3650-3673.

Zarei, M., Kirsch, S., Muthing, J., Bindila, L., and Peter-Katalinic, J. (2008). Automated normal phase nano high performance liquid chromatography/matrix assisted laser desorption/ ionization mass spectrometry for analysis of neutral and acidic glycosphingolipids. Anal Bioanal Chem 391, 289-297.

Zhang, H., Li, X.J., Martin, D.B., and Aebersold, R. (2003). Identification and quantification of N-linked glycoproteins using hydrazide chemistry, stable isotope labeling and mass spectrometry. Nat Biotechnol 21, 660-666.

Zhang, H., Singh, S., and Reinhold, V.N. (2005). Congruent strategies for carbohydrate sequencing. 2. FragLib: An MS ${ }^{\text {n }}$ spectral library. Anal Chem 77, 6263-6270.

Zhang, J., Lindsay, L.L., Hedrick, J.L., and Lebrilla, C.B. (2004a). Strategy for profiling and structure elucidation of mucin-type oligosaccharides by mass spectrometry. Anal Chem 76, 59906001. 
Zhang, J., Xie, Y., Hedrick, J.L., and Lebrilla, C.B. (2004b). Profiling the morphological distribution of O-linked oligosaccharides. Anal Biochem 334, 20-35.

Zhao, C., Xie, B., Chan, S.Y., Costello, C.E., and O'Connor, P.B. (2008). Collisionally activated dissociation and electron capture dissociation provide complementary structural information for branched permethylated oligosaccharides. J Am Soc Mass Spectrom 19, 138-150.
Address correspondence to: Joseph Zaia

Department of Biochemistry Boston University

670 Albany Street, Rm 509

Boston, MA 02118

E-mail: jzaia@bu.edu 